Villiger, L., Gischig, V. S., Kwiatek, G., Krietsch, H., Doetsch, J., Jalali, M., Amann, F., Giardini, D., Wiemer, S. (2021): Meter-scale stress heterogeneities and stress redistribution drive complex fracture slip and fracture growth during a hydraulic stimulation experiment. - Geophysical Journal International, 225, 3, 1689-1703.

https://doi.org/10.1093/gji/ggab057 


\title{
Metre-scale stress heterogeneities and stress redistribution drive complex fracture slip and fracture growth during a hydraulic stimulation experiment
}

\author{
Linus Villiger ${ }^{\oplus},{ }^{1}$ Valentin Samuel Gischig, ${ }^{2,3}$ Grzegorz Kwiatek, ${ }^{4}$ Hannes Krietsch, ${ }^{2,5,6}$ \\ Joseph Doetsch ${ }^{\bullet}, 2$ Mohammadreza Jalali, ${ }^{2,6}$ Florian Amann, ${ }^{2,6}$ Domenico Giardini ${ }^{2}$ and \\ Stefan Wiemer ${ }^{1}$ \\ ${ }^{1}$ Swiss Seismological Service, ETH Zurich, Sonneggstrasse 5, Zurich 8092, Switzerland.E-mail: linus.villiger@sed.ethz.ch \\ ${ }^{2}$ Department of Earth Sciences, ETH Zurich, Sonneggstrasse 5, Zurich 8092, Switzerland \\ ${ }^{3}$ CSD Ingenieure AG, Hessstrasse 27D, Bern 3097, Switzerland \\ ${ }^{4}$ Helmholtz-Center Potsdam, GFZ German Research Centre of Geosciences, Telegrafenberg, Potsdam 14473, Germany \\ ${ }^{5}$ iLF Consulting Engineers, Flurstrasse 55, Zurich 8048, Switzerland \\ ${ }^{6}$ Department of Engineering Geology \& Hydrogeology, RWTH Aachen, Lochnerstraße 4-20, Aachen 52056, Germany
}

Accepted 2021 February 8. Received 2021 January 17; in original form 2020 August 3

\begin{abstract}
SUMMAR Y
We investigated the induced seismicity, source mechanisms and mechanical responses of a decametre-scale hydraulic stimulation of a pre-existing shear zone in crystalline rock, at the Grimsel Test Site, Switzerland. The analysis reveals the metre-scale complexity of hydraulic stimulation, which remains hidden at the reservoir-scale. High earthquake location accuracy allowed the separation of four distinct clusters, of which three were attributed to the stimulation of fractures in the damage zone of the shear zone. The source mechanism of the largermagnitude seismicity varied by cluster, and suggests a heterogeneous stress field already prevailing before stimulation, which is further modified during stimulation. In the course of the experiment, stress redistribution led to the aseismic initiation of a tensile-dominated fracture, which induced seismicity in the fourth of the identified seismic clusters. The streaky pattern of seismicity separated by zones without seismicity suggests fluid flow in conduits along existing fracture planes. The observed submetre scale complexity questions the forecasting ability of induced seismic hazard at the reservoir scale from small-scale experiments.
\end{abstract}

Key words: Induced seismicity; Earthquake source observation; Creep and deformation; Fracture and flow; Permeability and porosity.

\section{INTRODUCTION}

Successfully creating an enhanced geothermal system (EGS) for electrical power and heat generation requires the enhancement of hydraulic conductivity and connectivity in the existing fracture networks of naturally low permeability basement rock at several kilometres depth. The method chosen to achieve this goal is called hydraulic stimulation and involves injecting fluids (e.g. water) at high pressure through a deep borehole (Hirschberg et al. 2014). This approach has been successfully applied in a handful of EGS systems around the world [e.g. Soultz-sous-Fôret, Rittershofen, Insheim (Genter et al. 2010; Baumgaertner et al. 2013; Baujard et al. 2017]. However, in other cases, especially near urban areas such as Basel in 2006 and Pohang in 2017 (Haering et al. 2008; Lee et al. 2019b), projects have failed because they were unable to create commercially viable reservoirs without also inducing felt or damaging earthquakes. Balancing permeability enhancement and seismic safety is urgently needed to facilitate the widespread use of EGS technology, but scientists and reservoir engineers have not yet been able to develop this successfully. Progress will require an improved understanding of the predominant physical mechanism responsible for induced seismicity and aseismic deformation during hydraulic stimulation, which is the primary target of our study.

While laboratory analysis and numerical simulations can help to understand the complex interactions of thermal hydraulic and mechanical (THM) processes, in situ observations and experiments are required for model calibration and validation, upscaling and proof of concept. While full-scale experiments at $3-5 \mathrm{~km}$ depth are extremely expensive and difficult to manage, closely monitored experiments at the decametre scale can be performed in underground laboratories (Gischig et al. 2019). The results of one such experiment conducted at the Grimsel Test Site (GTS) in the Swiss Alps are reported here (Fig. 1). The overall objective of the experiment 


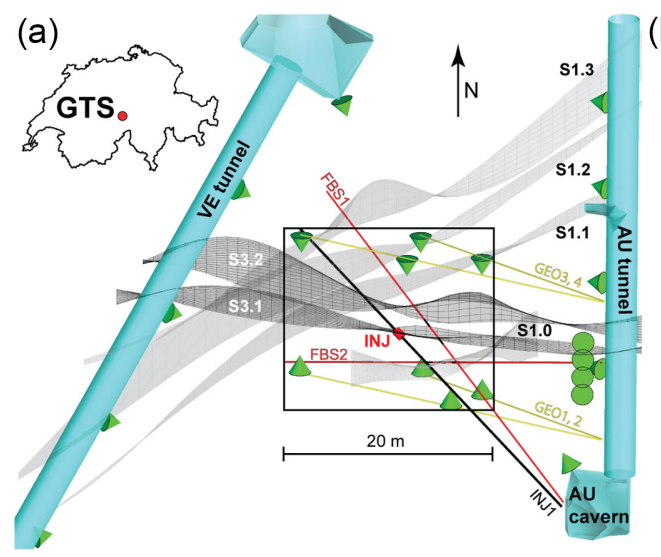

(b) Detail: Top view

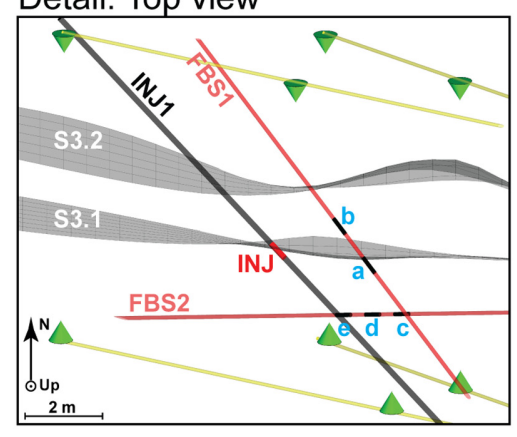

(c) Detail: West view

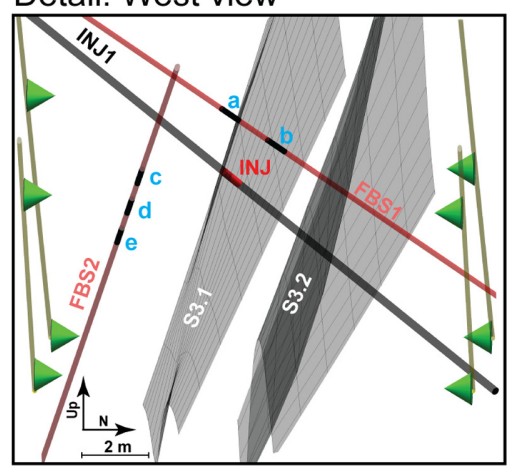

Figure 1. (a) Overview of the experimental volume (top view) at the GTS and the intersecting shear zone sets S1 and S3, injection borehole (INJ1), injection interval (INJ), strain monitoring boreholes (FBS1, 2, monitoring intervals are coloured in black) and the installed AE sensors (green cones) in tunnels and boreholes (GEO1-4). (b), (c) detail of top and west views.

sequence was to closely observe seismo-hydromechanical phenomena during hydraulic stimulation, and, by zooming into the details of these processes with a dense monitoring network, augment our understanding of them at the larger (i.e. full EGS) scale. Stress is a critical parameter linked to the evolution of deformation during fluid injections. Tectonic plate boundary forces and high topographies influence the stress field (Zoback et al. 1989). Variations in rock and fracture stiffness, contrasts in rheology and density, past and recent fault slip modify the stress filed further (Bruno \& Winterstein 1994; Heidbach et al. 2007; Wileveau et al. 2007; Lin et al. 2010; Blake 2013; Nie et al. 2013; McNamara et al. 2015). Moreover, it is very likely that stress perturbations occur on all scales, similarly to fault slip (Valley \& Evans 2010; Blake 2013).

In an EGS reservoir, numerous authors describe stress heterogeneities as changes in magnitude and rotation of principal stresses (Pahl et al. 1989; Bell et al. 1992; Wileveau et al. 2007; Valley \& Evans 2009, 2010, 2019). Based on wellbore failure analysis performed at the Soultz EGS site, Valley \& Evans (2010) conclude that the most prominent variations in horizontal principal stress orientation coincide with two major fracture zones intersected by the two analysed wells. One of these fracture zones intersects the wells, where they are only $20 \mathrm{~m}$ apart. However, large scale variations in horizontal principal stress orientation and magnitude only partially correlate between the two wells.

At the GTS, the prevailing stress field is strongly affected by topography, such that none of the principal stress directions is vertical (Krietsch et al. 2018b). Krietsch et al. (2018b) observed a drop in the minimum principal stress magnitude from 8.6 to $\sim 3 \mathrm{MPa}$ within $12 \mathrm{~m}$ and a rotation of the principal stress axes as the shear zone, stimulated in the experiment reported here, is approached. The influence of tunnels and boreholes on the stress field in the volume of stimulation can be considered as minor. The reason for this is that the rock around excavation shows no or only minor excavation damage zone, and its behaviour can essentially be considered elastic. According to Kirsch (1898), in an isotropic elastic medium, tunneling induced stress redistribution affect the in situ stress only until two tunnel diameters away from the excavated tunnel (i.e. $\sim 10 \mathrm{~m}$; closest distance tunnels - stimulated volume: $20 \mathrm{~m}$ ).

Since hydraulic stimulation is inevitably accompanied by fracture slip (i.e. often associated with seismicity), such high-pressure fluid injections conceivably modify the already prevailing heterogeneous stress field (Schoenball et al. 2014). Injections primarily lead to an increase in pore pressure and thus to a reduction of the effective normal stresses along pre-existing fractures. As a consequence of this reduction in the effective normal stress, slip (both seismic and aseismic) and/or opening of fractures may occur. Such fracture dislocation causes instantaneous stress changes in the surrounding regions (Schoenball et al. 2012). Furthermore, volumetric expansion of the pressurized rock mass around the injection interval induces stress changes at larger distances from the injection location through poroelastic stress transfer (Segall \& Lu 2015; Goebel et al. 2017). Fracture orientation in the modified stress field, geological properties (e.g. frictional properties, fault zone architecture) and the injection strategy determine whether a fracture dislocates aseismically or seismically (Guglielmi et al. 2015). Bhattacharya \& Viesca (2019) suggest that aseismic deformation may outpace pore-fluid migration. While the general factors determining mechanical fluid rock interactions are well known, we still lack the ability to accurately forecast how fluid injection will evolve, and how to guide it to achieve the optimum permeability enhancement with an acceptable level of risk for induced damaging earthquakes. The situation is not that different from natural earthquakes, where the general physical mechanisms governing earthquake-earthquake interactions are known (King et al. 1994), but are not fully utilized for earthquake predictability (Nandan et al. 2019).

The source mechanisms of induced earthquakes are closely coupled to the local, momentary stress state (Martinez Garzon et al. 2017) and can be an important source of information on reservoir properties. Through stress inversion of focal mechanisms Schoenball et al. (2014) observed stress changes during fluid injection of tens of $\mathrm{MPa}$, changing the stress regime from normal mixed with strike-slip faulting (NF/SS) to pure NF. They attributed these stress changes to large-scale aseismic deformation. Schoenball et al. (2012) and Catalli et al. (2013) suggested that induced earthquakes lead to static stress transfer, which can effectively help to induce further earthquakes. Also, spatial variations of the principal stress axis, or transient variations related to injection rates/volume are observed through the inversion of source mechanisms (Martinez Garzon et al. 2013; Martinez Garzon et al. 2014). The magnitude of the induced seismic event may also be related to the prevailing stress regime revealed by source mechanisms (Schorlemmer et al. 2005; Martinez Garzon et al. 2016). Furthermore, the opening component, inferred from seismic moment tensor analysis, may be sensitive to a pore pressure increase and thus restricted to the near well-bore area 
(Martinez Garzon et al. 2017). However, distinguishing the influence of the prevailing stress field from its injection-induced modification through focal mechanisms remains challenging. One reason for this is that information on the heterogeneous pre-stimulation stress field is limited to a few observation points.

Here, we analyse the source mechanisms, the spatio-temporal evolution of seismicity in combination with pressure and the strain evolution observed during a hydraulic stimulation experiment conducted in crystalline rock at the decametre scale at the Grimsel Test Site (GTS), Switzerland. The experiment (labelled HS4) was performed on 2017 February 9 as part of the In situ Stimulation and Circulation (ISC) project (Amann et al. 2018). The rich seismicity data set observed during this particular experiment allows addressing the questions to what degree seismicity characteristics are predictable from detailed pre-experimental characterization and if seismicity is sufficiently scale invariant to be readily upscaled to the field scale. The injection interval contained both, a low-permeable fault core and a surrounding brittle damage zone of an extensive (i.e. several metres wide and up to a kilometre long (Keusen et al. 1989) shear zone. Considering the stress-state measured at the targeted shear zone prior to the experiment, right-lateral to oblique thrust faulting is conceivable as fault mechanism. Our observations show highly complex seismicity patterns and source mechanisms that arise from the interplay between (1) pre-existing fractures within the damage zone, (2) a prevailing stress field that is heterogeneous on the metre-scale and (3) a further, transient modification of the stress field during stimulation.

\section{MATERIALS AND METHODS}

\subsection{Study site}

The injection experiment was carried out with approximately $480 \mathrm{~m}$ of overburden (Fig. 1). The experimental volume, located in granodioritic and granitic rocks (Wenning et al. 2018), is intersected by four shear zones with a ductile deformation history (referred to as S1 with an orientation of $142^{\circ} / 77^{\circ}$ ), and two shear zones with a brittle-ductile deformation history (referred to as S3.1 and S3.2, $183^{\circ} / 65^{\circ}$ ). The cores of the two S3 shear zones, separated by $\sim 2 \mathrm{~m}$, are sheared meta-basic dykes associated with highly permeable and compliant fractures (Jalali et al. 2018; Krietsch et al. 2018a).

An extensive stress characterization campaign (Krietsch et al. (2018b) used different stress measurement methods to investigate the stress state about $40 \mathrm{~m}$ south the target shear zone S3.1, as well as in the proximity of the shear zone (i.e. about $5 \mathrm{~m}$ from the shear zone and $20 \mathrm{~m}$ from the injection interval). The stress state at greater distance from the shear zone (here termed 'unperturbed stress state') significantly differs from the one close the shear zone (here termed 'perturbed stress state') possibly due to past fault slip and stiffness contrasts between the shear zone and the surrounding host rock (Krietsch et al. 2018b; Doetsch et al. 2020). The principal components of the unperturbed and the perturbed stress state are $\sigma_{1}$ $=13.1 \mathrm{MPa}, \sigma_{2}=9.2 \mathrm{MPa}, \sigma_{3}=8.7 \mathrm{MPa}$ and $\sigma_{1}=13.1 \mathrm{MPa}, \sigma_{2}$ $=8.2 \mathrm{MPa}, \sigma_{3}=6.5 \mathrm{MPa}$, respectively (Fig. 2b). The spatial heterogeneity of the stress field on the decametre scale was confirmed by the stress information extracted from the various stimulation experiments (Krietsch et al. 2020a,b; Dutler et al. 2019).

\subsection{Injection experiment and monitoring}

The 1-m-long injection interval covered the shear zone S3.1 (Fig. 1a, INJ), which has a pre-stimulation injectivity of $0.951 \mathrm{~min}^{-1} \mathrm{MPa}^{-1}$ (transmissivity: $1.2 \times 10^{-7} \mathrm{~m}^{2} \mathrm{~s}^{-1}$, Krietsch et al. 2020a). The injection involved $1.3 \mathrm{~m}^{3}$ water introduced in four cycles (Cy1-Cy4, Fig. 6a). The pressure controlled cycles $\mathrm{Cy} 1$ and $\mathrm{Cy} 2$ were conducted to infer the pre-stimulation jacking pressure and the initial injectivity of the target structure. Cy3 was the actual stimulation cycle, in which the bulk part of the fluid was injected in a ratecontrolled fashion. The flow-rate was increased in $51 \mathrm{~min}^{-1}$ increments from 10 to $251 \mathrm{~min}^{-1}$. Injection cycle $\mathrm{Cy} 4$ (mixed pressure and rate controlled for technical reasons) aimed at determining the post-stimulation jacking pressure and injectivity of the target structure [post stimulation injectivity and transmissivity: $0.951 \mathrm{~min}^{-1}$ $\mathrm{MPa}^{-1}, 1.2 \times 10^{-7} \mathrm{~m}^{2} \mathrm{~s}^{-1}$ (Krietsch et al. 2020a)]. Each injection cycle was followed by a shut-in and venting phase.

Seismicity was monitored with 26 Acoustic Emission (AE) sensors (type: GMuG MA-BLw/s-7-70-xx), eight of which were deployed in boreholes (Fig. 1a, green cones in borehole GEO1-4). The borehole AE sensors were distributed around the injection interval at euclidean distances of 8.9-15.7 m (Villiger et al. 2020).

Longitudinal strain was recorded along boreholes FBS1 and FBS2 using $1 \mathrm{~m}$ long Fiber-Bragg-Grating strain sensors (Fig. 1a). The strain sensors for borehole FBS1, which intersects the target shear zone S3.1, were located south and between the S3 shear zones (sensors a and b in Fig. 1a, respectively). The strain monitoring borehole FBS2 is sited parallel to the S3 shear zones and contains the sensor c, d and e shown in Fig. 1(a).

\subsection{Seismic moment tensor (MT) inversion}

During the experiment, the locations of 3094 out of 5607 detected seismic events were identified. The magnitudes ranged from $M_{\mathrm{A}}$ -5.5 to -2.75 (Villiger et al. 2020). Out of 3094 events listed in the seismicity catalogue and shown in Fig. 3, 103 events with $\geq 10$ $P$-wave amplitudes were considered for MT inversion and the associated refinement procedure. We corrected the input amplitude data for frequency independent attenuation (see supporting material S2 for details) and the influence of incidence angle to axis of the single-component AE sensors [see S3 cf. Manthei et al. (2001); Kwiatek et al. (2011), for details]. The $P$-wave amplitude, A $(t)$, in the time domain can be expressed as:

$A(t)=A_{S}(t) * g(t) * i(t) * s(t)$

The symbol '*' denotes convolution in the time domain. $A_{S}(t)$ represents the amplitude at the source. The path effects $g(t)$ are modelled through geometrical spreading $\propto \frac{1}{r}$ and an attenuation term, $e^{\frac{\pi r f}{Q_{P} v_{P}}}$, with $\mathrm{r}$, being the source-receiver distance, $f=7.5 \mathrm{kHz}$ represents the dominant frequency, $Q_{P}=60$ is the frequency independent quality factor (see supplementary material S2 for its determination), and $v_{P}=5030 \mathrm{~m} \mathrm{~s}^{-1}$ is the $P$-wave velocity (Villiger et al. 2020). The variable $i(t)$ in eq. (1) represents the effect of AE sensors (i.e. the instrument response) on the recorded amplitude. It is not possible to infer the instrument responses of the deployed AE sensors. We only account for the known angle-dependent sensitivity variations of AE sensors (Manthei et al. 2001), using in situ determined incidence angle-dependent amplitude correction factors (see S3 for more information).

Source mechanisms were determined using the hybridMT software package (Kwiatek et al. 2016). The algorithm uses amplitudes of first motion $P$ waves along with their polarity to 
(a)

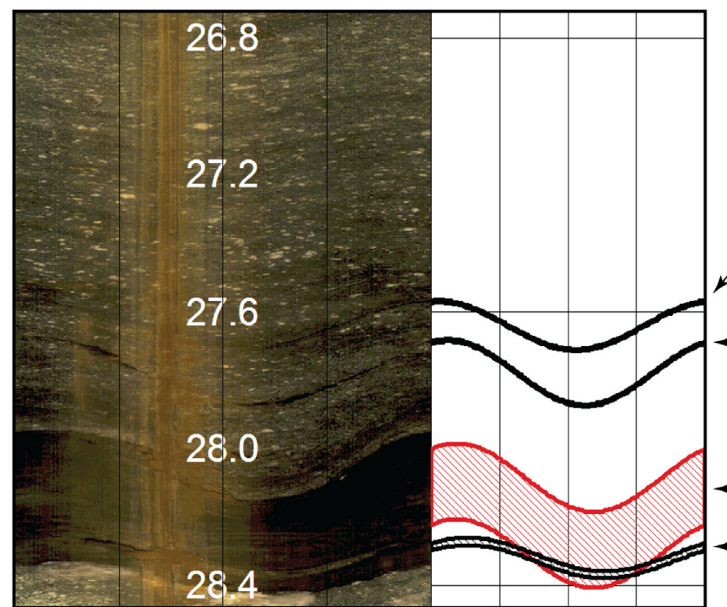

(b)

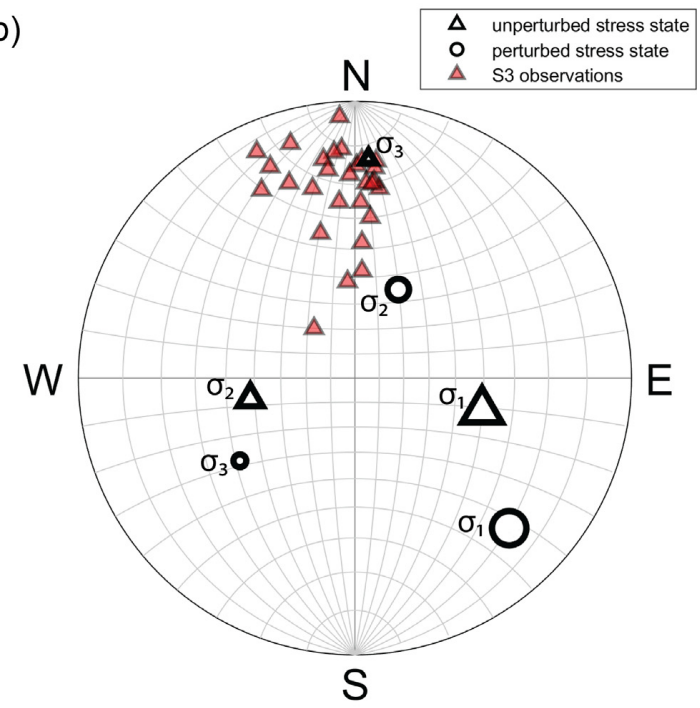

Figure 2. (a) Optical televiewer log of injection interval (INJ). The meta-basic dyke is clearly visible as a black band associated with several subparallel fractures. (c) The unperturbed and perturbed stress states with orientations of observations of the S3 shear zones in a lower hemisphere stereographic projection.

(a) Top view

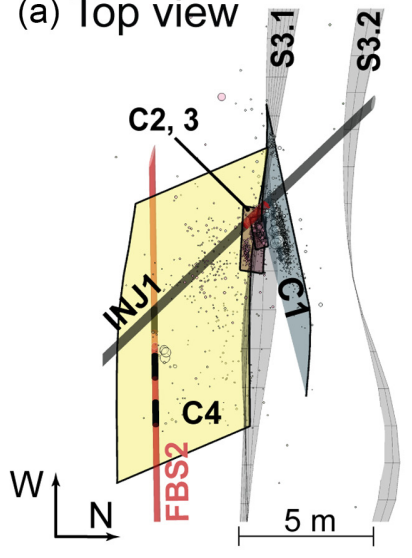

(c)

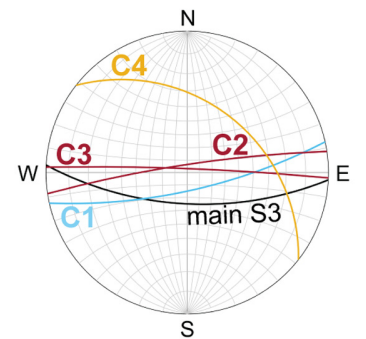

(b) West view

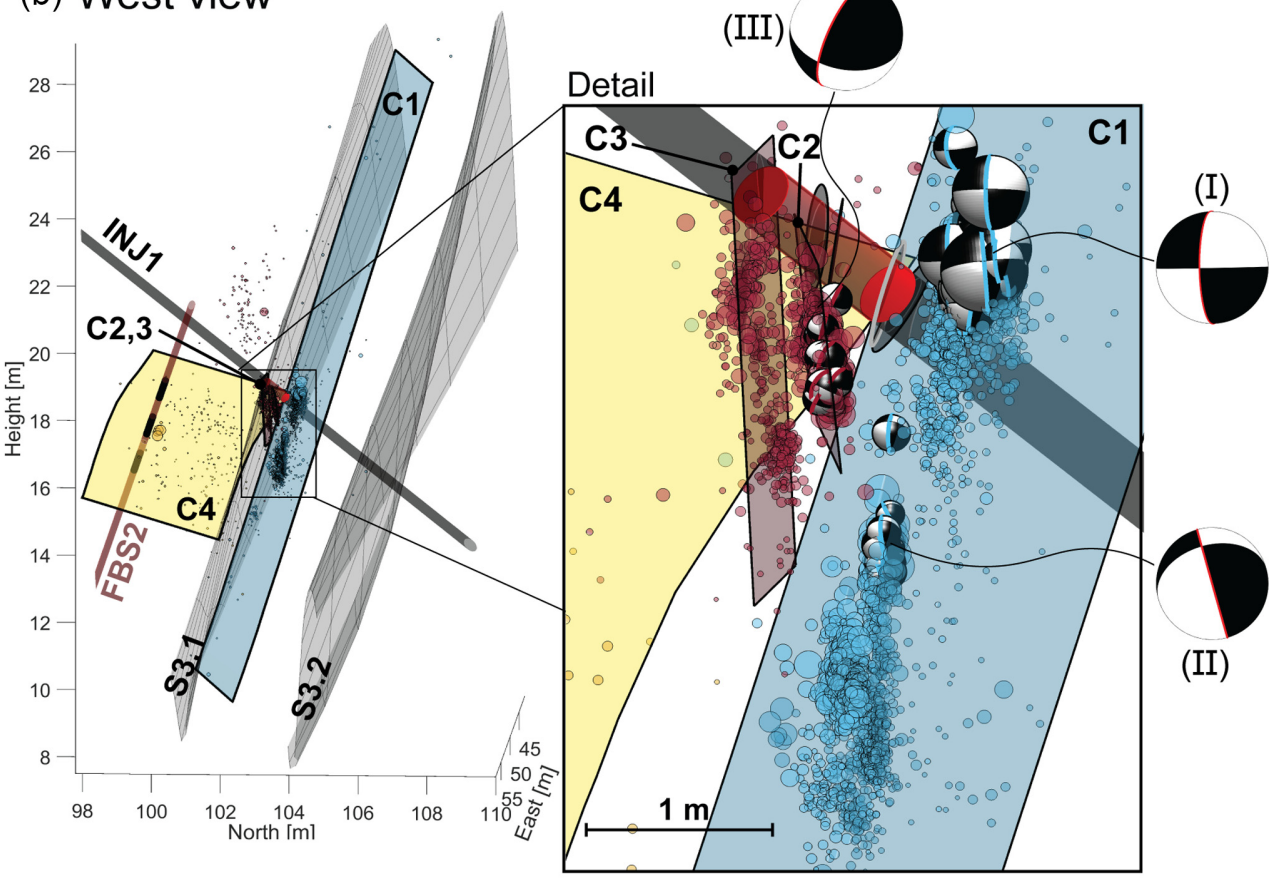

Figure 3. 3-D overview figure in (a) top and (b) side view of the injection borehole (INJ1) and the injection interval (red), the strain monitoring borehole (FBS2) and the two subparallel shear zones S3.1 and S3.2 along with the three distinct seismicity clusters and their best fitting planes. The detail view in (b) shows the seismicity immediately around the injection interval, along with the inferred source mechanisms. Focal mechanism I, II and III are representative mechanisms of cluster $\mathrm{C} 1$, upper and lower patch and cluster $\mathrm{C} 2$, respectively. The fault plane of each source mechanism is indicated by a coloured circle. (c) Orientations of the cluster planes in a lower hemisphere stereographic projection.

resolve for double-couple constrained (DCMT) and full moment tensors (FMT). Using an iterative procedure (see S5 for the determined correction factors and polarity matches), the software accounts for poorly known paths, site and sensor effects by taking advantage of common seismic ray paths of events forming a cluster (Andersen 2001).
The Bayesian Information Criterion (Cesca et al. 2013) was used (see S4) to decide whether a DCMT or a FMT solution is preferable. For each resulting MT, we sampled the MTs 100 times using $P$-wave amplitude data randomly perturbed by 10 per cent (Stierle et al. 2016) to simulate the effect of noise and evaluate the uncertainty of determined DCMTs and FMTs. The initial 103 seismic 
events considered for MT inversion were reduced to 84 MTs (35 DCMTs and 49 full FMTs) based on the quality criteria described in S6.

\section{RESULTS}

\subsection{Spatial distribution of seismicity}

The majority ( 97.7 per cent) of all located seismicity was induced during injection phases. The seismicity formed four distinct clusters (C1-C4, Fig. 3). Here, we use the term 'cluster' for events aligned along a distinct plane, and the term 'patch' is used for dense subgroups of events within a cluster.

The main cluster $\mathrm{C} 1$ (coloured in blue in Fig. 3) consists of 2096 events, and has a $20 \mathrm{~m}$ vertical and $7.5 \mathrm{~m}$ horizontal extent. Although it is closely associated with the shear zone S3.1 and shares a similar dip angle, it forms a steep angle of about $20^{\circ}$ with the target shear zone S3.1 (i.e. the target shear zone because the injection interval covered the $\mathrm{S} 3.1$ shear zone, see also Fig. 1b). All seismicity is located north of the S3.1 shear zone and stops immediately at the intersection line between the cluster plane and the shear zone plane. The $\mathrm{C} 1$ cluster is associated with the fracture north of S3.1 (Fig. 1b) and contains two patches with high seismicity density that are vertically offset by about $2 \mathrm{~m}$ with an identical orientation (dip direction/dip: $169^{\circ} / 76^{\circ}$ ). From the in-plain view (Fig. 4a, panel $\mathrm{C} 1$ ), we observe only sparse seismicity in the immediate vicinity of the injection interval (INJ); the two patches extend to about $2 \mathrm{~m}$ away from the injection interval. Both patches are elongated with the longest axis dipping 20-35 , and feature striped substructures. While the upper patch of $\mathrm{C} 1$ does not show a clear propagation direction, the lower patch of seismicity expands downwards to the east. The largest seismic magnitudes induced in the experiment are observed in the upper patch of cluster $\mathrm{C} 1$. The large magnitudes within each of the patches are grouped at the upper borders.

South of the target shear zone, two clusters were induced (C2, C3) in close proximity to the injection interval. These two clusters $\left(\mathrm{C} 2,341\right.$ events, $351^{\circ} / 84^{\circ}$; $\mathrm{C} 3,378$ events, $\left.2^{\circ} / 87^{\circ}\right)$ are subparallel to the target shear zone and offset by $0.5 \mathrm{~m}$ along the borehole axis. Along the upward extension of these two clusters, a more diffuse seismicity cloud with low event density formed. C2 and C3 are associated with the two fractures south of the target shear zone (Fig. 1b).

Cluster C2 (Fig. 4b) is located about $0.2 \mathrm{~m}$ away from the injection interval. Again, the seismicity forms an elongated patch with the long axis dipping $35^{\circ}$ towards the east with seismicity propagating down- and eastwards. Seismicity of cluster C3 (Fig. 4c) exhibits small elongated patches, also dipping towards the east but without a propagation trend. The magnitudes of seismicity in cluster $\mathrm{C} 3$ are lower than those in $\mathrm{C} 1$ and $\mathrm{C} 2$.

A fourth cluster (C4, 208 events) was induced below the injection borehole, that is it has no immediate hydraulic connection to the injection interval. The plane fitted through this cluster is oriented $38^{\circ} / 37^{\circ}$. The cluster appeared at the $724 \mathrm{~L}$ injected volume, and initiated at about the elevation of the lower patch of cluster $\mathrm{C} 1$ (Fig. 4d). Only small events were induced, except for four stronger ones that occurred close to the borehole FBS2. Since these events are much larger in magnitude than the rest of the cluster and located at the borehole FBS2, we assume that their occurrence is due to near borehole-effects of the cemented strain monitoring borehole and of an artificial nature. The spatial extent of the remaining small magnitude events is more than twice that of the seismicity associated with clusters $\mathrm{C} 1, \mathrm{C} 2$ and $\mathrm{C} 3$. The seismic events propagated from the west towards the east with time, when the injected fluid volume rose from 724 to 9781 . Some seismic events were also induced in the last injection cycle (i.e. the Cy 4 induced dark red events in Fig. 4d).

\subsection{Fault plane solutions}

There were 56 and 28 MTs successfully inferred for the seismic events in clusters $\mathrm{C} 1$ and $\mathrm{C} 2$, respectively (Fig. 3). The fault planes of the MTs were identified as subparallel to the orientation of the cluster that the respective seismic event belongs to (see supporting material S7). Seismic events with inferred MTs are often found in spatially dense subclusters featuring homogeneous fault plane solutions (see Fig. 5 for a cluster-dependent overview of MTs, including faulting styles). The mean fault plane solution of the upper patch of $\mathrm{C} 1$ (dip direction: $8^{\circ} \pm 11^{\circ} / 189^{\circ} \pm 7^{\circ}$, dip: $84^{\circ} \pm 4^{\circ}$, rake: $-99^{\circ} \pm 9^{\circ} / 100^{\circ} \pm 5^{\circ}$ ) reflects steeply dipping normal or thrust faulting (supporting material S8). For MTs from the lower patch of $\mathrm{C} 1\left(2^{\circ} \pm 5^{\circ} / 185^{\circ} \pm 10^{\circ}, 73^{\circ} \pm 9^{\circ},-136^{\circ} \pm 6^{\circ} / 122^{\circ} \pm 18^{\circ}\right)$ we observe right-lateral oblique normal to thrust faulting mechanisms. Using a simple two block model separated by the $\mathrm{C} 1$ clusterplane, the block in the south moves upwards with respect to the block in the north. In the region of the lower patch of $\mathrm{C} 1$, the dip and rake angles deviate slightly from the vertical. The mean fault plane properties of $\mathrm{C} 2$ do not vary dramatically $\left(197^{\circ} \pm 10^{\circ}, 67^{\circ} \pm 5^{\circ},-93^{\circ} \pm 13^{\circ}\right)$ compared to the MTs of $\mathrm{C} 1$ and suggest a dominance of normal faulting kinematics. When we consider two blocks separated by the cluster $\mathrm{C} 2$ plane, the block in the south moves downward compared to the upward movement of the block in the north (compare also slip directions of cluster $\mathrm{C} 1$ and $\mathrm{C} 2$ indicated with black arrows in Figs $4 \mathrm{a}$ and $\mathrm{b}$ ). The isotropic components of the full MT solutions range from 1 to 26 per cent with no observable temporal trend, but do tend to increase with distance from the injection interval, and are particularly high for events in the lower patch of cluster C1 (see supporting material S11).

\subsection{Temporal seismo-hydromechanical observations}

The onset of seismicity during cycle Cyl occurs at around 5.5 $\mathrm{MPa}$ injection pressure (Fig. 6a). The onset pressure increases during successive cycles. In cycle Cy1, cluster $\mathrm{C} 2$ was activated earlier than cluster $\mathrm{C} 1$, while the opposite is true during cycle Cy2. Seismicity rates and magnitudes of induced events increase at the peakinjection of both cycle Cy1 and Cy2.

During the main stimulation cycle $\mathrm{Cy} 3$, only sparse seismicity was induced during the first constant-rate step (Fig. 6a). Seismicity rates and magnitudes increased with each rate step (Cy 3.2-3.4), but then decayed along with the injection pressure during each rate step. Cluster C4 was induced shortly before the last rate step in $\mathrm{Cy} 3$. During cycle $\mathrm{Cy} 4$, seismic activity began in the last injection step (except for one event). Again, both the seismicity rate and magnitude decay with the ongoing injection. During this cycle, cluster $\mathrm{C} 1$ was predominately reactivated; this cluster also contains the experiment's largest magnitude event (i.e. $M_{\mathrm{A}}-2.8$ ).

The strain sensors between the S3 shear zones (sensors a and b, Fig. 6b) show extensional strain, while outside the shear zones compression is observed. Strain signals increase with increasing injection parameters (i.e. injection volume, injection rate, Fig. 6b). 
(a) $\mathrm{C} 1$

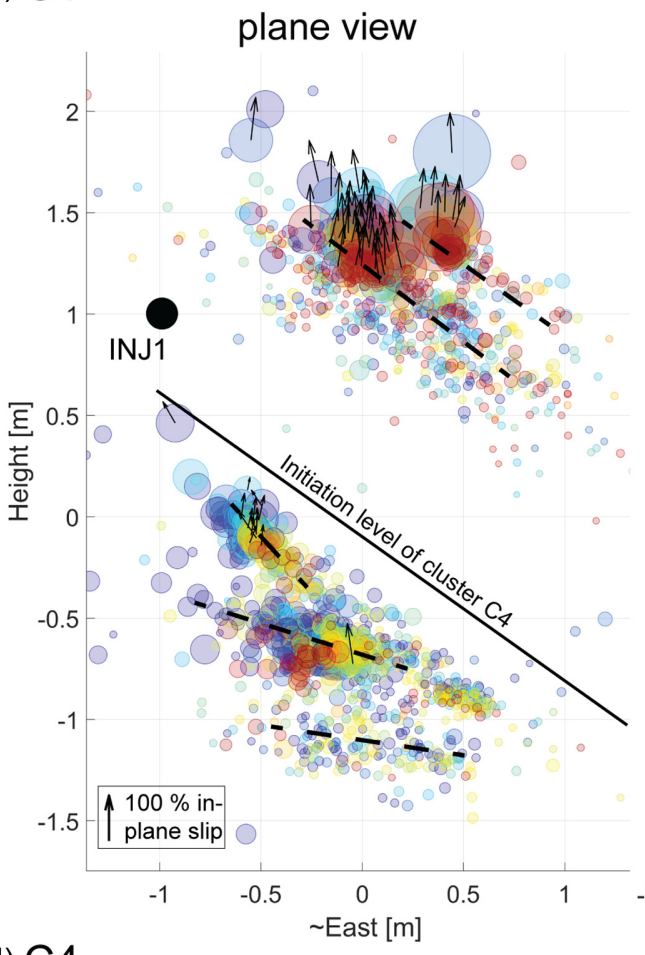

(d) $\mathrm{C} 4$

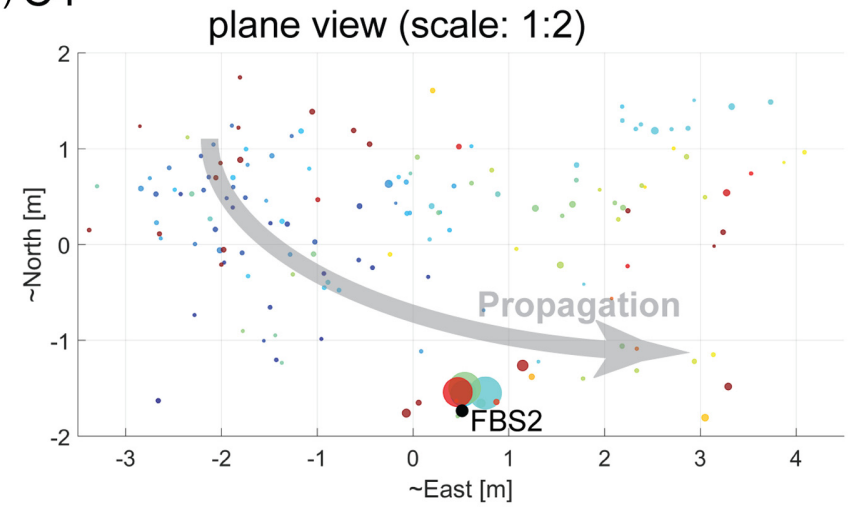

(b) $\mathrm{C} 2$
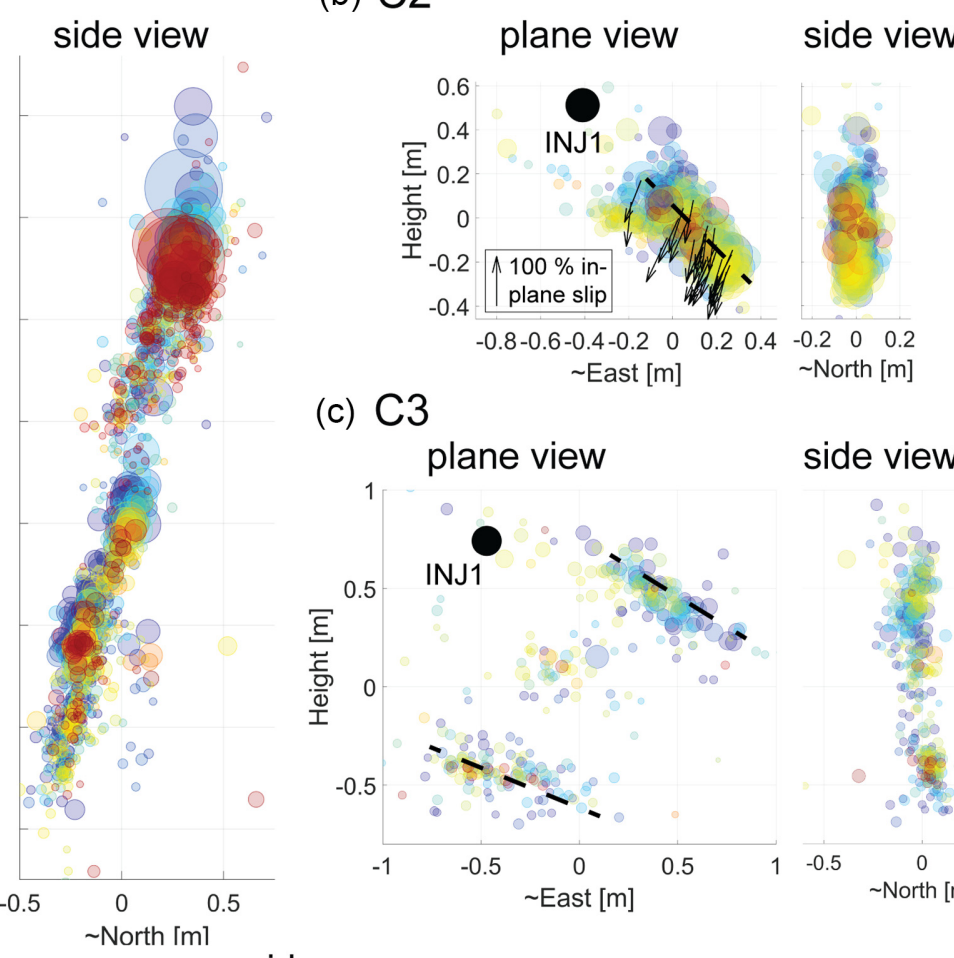

(c) $\mathrm{C} 3$

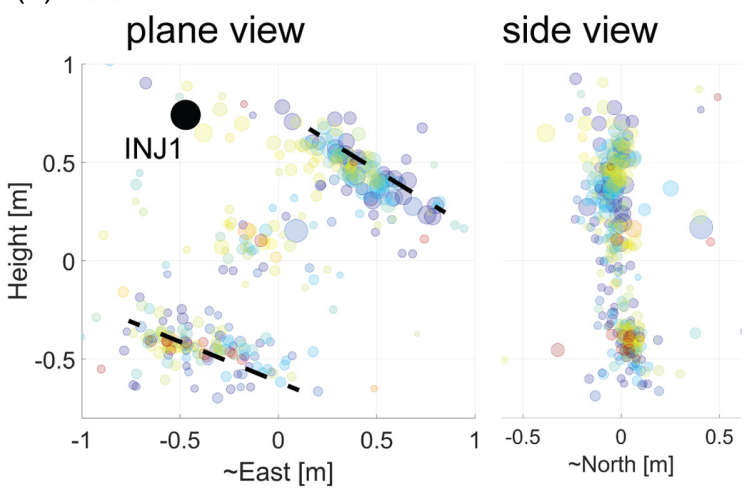

side

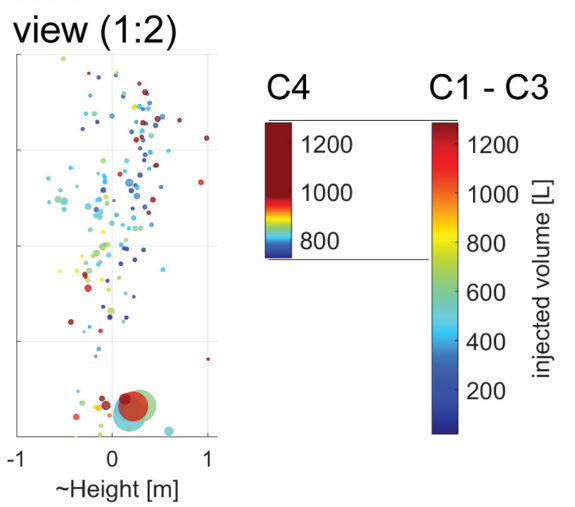

Figure 4. (a-d) Projection of seismicity clusters onto their best-fitting plains. The seismic events are colour coded according to the cumulative injected volume. The source radii of the seismic events were calculated following Eshelby (1957) assuming a static stress drop of 2.5 MPa. Slip directions inferred from MTs are indicated as black arrows in a 'south-view' perspective. Streaks of seismicity in cluster C1-C3 are indicated by dashed lines.

The strain signals along borehole FBS2, located south and parallel to the target shear zone, did not exceed $8 \mu \varepsilon$ in the first two injection cycles. During the main injection cycle, at an injected volume of 620 1, strain sensor d indicates a rising extensional strain signal (Fig. 6b). The seismicity of cluster $\mathrm{C} 4$, that eventually hits sensor d, starts at 7241 . After this, the strain rate on sensor d accelerates in two phases. The second correlates with the appearance of seismicity close to the sensor - and reaches an extension of almost $0.4 \mathrm{~mm}$ at the end of cycle Cy3. Five minutes after the onset of strain at sensor $\mathrm{d}$, the first seismic event of cluster $\mathrm{C} 4$ is induced $3.5 \mathrm{~m}$ away from sensor $\mathrm{d}$, and 3 minutes later the first seismic event hits strain sensor $\mathrm{d}$. In total $15 \mathrm{~min}$ pass from the onset of strain to the full extensional strain magnitude at sensor $\mathrm{d}$ at the end of the main stimulation cycle Cy3. The adjacent strain sensors c and e in FBS2 exhibit contraction and extension after the strain rate at sensor $\mathrm{d}$ accelerates. Simultaneous to the strong extension of sensor d, the sensors $\mathrm{c}$ and e show contraction. The strong extension observed at sensor $\mathrm{d}$ also initiates an acceleration of the extensional strain in FBS1 (sensors a, b). During the last injection cycle Cy4 sensor d in FBS2 extends again, but contracts before the highest injection rate is reached. Residual extension, measured $16 \mathrm{hr}$ after the experiment, remains $>0.1 \mathrm{~mm}$ for sensor $\mathrm{d}$.

\section{DISCUSSION}

The overall objective of our study is to enhance our understanding and ability to forecast the hydromechanical processes governing high pressure fluid injections into granitic rock. A primary outcome of our analysis on a decametre scale experiment is the realization of 

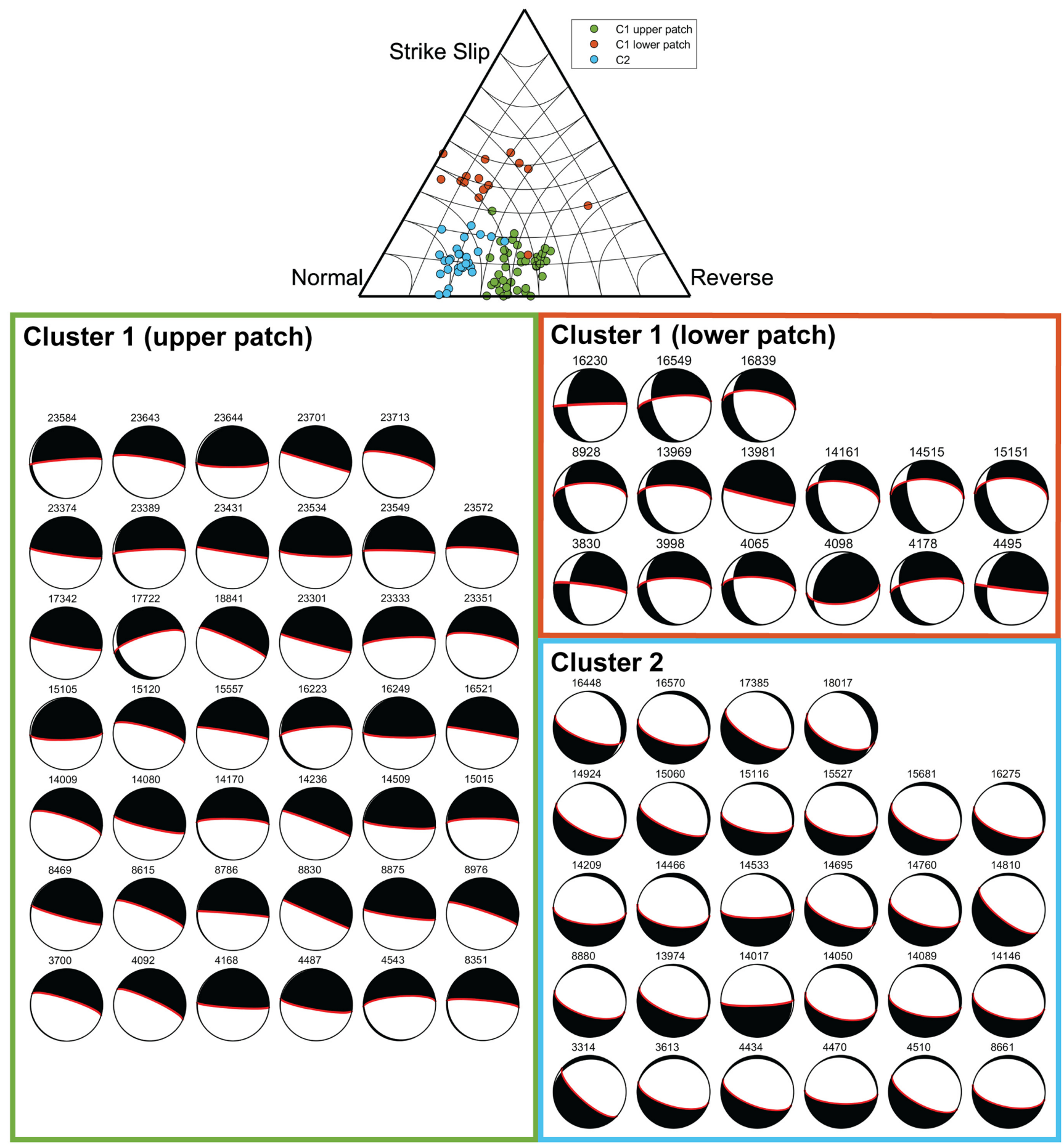

Figure 5. Double-couple constrained, lower hemisphere stereographic projections of all inferred MTs separated in clusters and patches, along with the corresponding faulting styles, after the convention introduced by Frohlich (1992). The failure plain in each beach ball is indicated by a red line.

the complexity of fluid-rock interactions and the resulting seismic and aseismic deformation. At the GTS, we are in a unique position to observe seismo-hydromechanical processes using nearby and dense multiparameter instrumentation. Owing to our dense multiparameter instrumentation during the stimulation experiment, we find that by viewing processes at the micro- and macroscale with such resolution, we can observe the complexity in seismicity and faulting styles that are not consistent with a simple fault slip model. In order to explain the observations of temporal and spatial clustering and migration of seismicity, the hydraulic data, observed deformation, fracture orientation and MTs documented in Figs 3 and 5, we need to consider stress heterogeneity in space and time as a key driver controlling seismicity evolution. Our results thus introduce substantial limitations on the ability to forecast the evolution of seismic sequences during reservoir stimulation, given that knowledge of the stress heterogeneity in the host rock is always very limited. 


\subsection{Fault slip model}

In Fig. 8 we propose a conceptual model in cross-sectional view that summarizes and contextualizes our observations. The highpressure water injection of $1.3 \mathrm{~m}^{3}$ into a brittle-ductile shear zone led to high seismic activity along fractures of the damage zone, whereas seismicity was entirely absent along the fault core (i.e. a metabasic dike deformed in ductile manner) itself. Most seismicity ( $\sim 70$ per cent) was observed in cluster $\mathrm{C} 1$ [cumulative seismic moment: $2.1 \times 10^{6} \mathrm{Nm}$, the calibration of the AEs was performed in Villiger et al. (2020)], which propagated between the two EWstriking shear zones S3.1 and S3.2 at a steep angle. The seismicity thus indicates activation of a fracture linking the two S3 shear zones rather than activation of the S3.1 core that was targeted. Indeed, hydraulic tests performed within the two S3 shear zones and documented by Brixel et al. (2020) confirm the existence of these highly permeable linking fractures between the two $\mathrm{S} 3$ shear zones. However, despite the high seismic response during this injection compared to injections in the same experimental volume (Villiger et al. 2020), injectivity and transmissivity was not increased during this injection (Krietsch et al. 2020b). We observe that slip along fractures and seismicity is neither focused on the fault core, which is intersected by quartz-filled fractures of less than $1 \mathrm{~mm}$ aperture, nor on the interface between the fault core and the damage zone. Instead seismicity and fracture dislocation occurred exclusively on fractures in the damage zone adjacent to the fault core. This is in agreement with the fault model by Wenning et al. (2018), which suggests lower permeability of the fault core compared to the fractures in the damage zone.

The source mechanism of the two patches of cluster $\mathrm{C} 1$ indicate an upward movement of the rock block in the south with respect to the northern block. The lower patch shows a minor right-lateral strike-slip component (i.e. the southern block moves towards west). This right-lateral oblique thrust faulting mechanism fits with the source mechanism on cluster plane $\mathrm{C} 1$ that is expected from the stress measurements recorded about $20 \mathrm{~m}$ from the injection site [i.e. the perturbed stress state (Krietsch et al. 2018b)]. Note, however, that this is not the case for the other patch of $\mathrm{C} 1$ and for cluster $\mathrm{C} 2$, because the inferred slip directions deviate from the predicted slip directions of the perturbed stress state (Fig. 7a). Considering the Mohr-Coulomb failure criterion assuming the perturbed stress state, failure pressure for almost all the inferred structures was below $7 \mathrm{MPa}$ (Fig. 7b). Recall that the maximum injection pressure reached during injection is $\sim 7 \mathrm{MPa}$ in the injection interval. The fluid pressure at the cluster $\mathrm{C} 1$ and $\mathrm{C} 2$, being at distances less than $2 \mathrm{~m}$ away from the injection, is likely to be close to this maximum pressure. Thus, the perturbed stress field is in agreement with the occurrence of slip along these fractures.

Cluster $\mathrm{C} 4$ formed between the upper and the lower patch of cluster $\mathrm{C} 1$ - specifically at the upper edge of the lower patch - at approximately a $90^{\circ}$ angle to $\mathrm{C} 1$. High extension rates observed at strain sensor d in borehole FBS2 (Fig. 6b) accompanied by low-magnitude seismic events propagating from west towards east suggests tensile dominated deformation. Also, in the region of sensor $\mathrm{d}$, where the peak extensional deformation of almost $0.4 \mathrm{~mm}$ was observed, no pre-existing fracture was identified in borehole logs prior to stimulation. This suggests the initiation of a new tensile dominated fracture plane along the $\mathrm{C} 4$ cluster plane. The fracture initiation was largely aseismic; around 3 min elapsed from the fracture initiation until the first seismic event hit the strain sensor that recorded the initial aseismic strain signal and more than 15 min elapsed from this aseismic fracture initiation to the maximum opening. This highlights the importance of aseismic processes in understanding stimulation processes, a fact also observed in laboratory-experiments (Goodfellow et al. 2015) as well as at the field scale (Cornet et al. 1997). We also acknowledge that in this stimulation experiment more than 99 per cent of deformation was aseismic (Villiger et al. 2020). However, we still suggest that the initiation of cluster $\mathrm{C} 4$ can be interpreted as a consequence of the difference in the cumulative seismic moment $M_{0}$ of the upper patch of cluster $\mathrm{C} 1\left(1.1 \times 10^{6} \mathrm{Nm}\right)$ compared to the lower patch $\left(6.1 \times 10^{5} \mathrm{Nm}\right.$, Fig. 8$)$. As the cumulative seismic moment is almost double in the upper patch, it seems reasonable to assume that the area around this patch experienced more dislocations than the area around the lower patch.

Using a rough scoping calculation to estimate the tensile stresses originating from slip differences between the two patches and comparing it to the tensile strength of the granitic rock at the GTS, the initiation of a tensile fracture seems reasonable. With $M_{0}=\mu A D$, where $\mu$ is the shear modulus, chosen to be $15 \mathrm{GPa}, A$ represents the seismically sheared area and is estimated as $2 \mathrm{~m}^{2}$ for each of the two patches, the slip difference between the upper and the lower patch is $16 \mu \mathrm{m}$. Assuming $16 \mu \mathrm{m}$ slip difference across $2 \mathrm{~m}$ patch separation results in $8 \mu \epsilon$, which leads to a tensile stress in the order of $200 \mathrm{kPa}$, assuming a Young's moduli of $25 \mathrm{GPa}$. Given the high ratio of aseismic deformation observed in the experiment, slip values may be almost 100 times larger, resulting in tensile stress levels of up to $20 \mathrm{MPa}$, which exceeds the tensile strength of $\sim 15$ and $\sim 6 \mathrm{MPa}$, normal and in direction of foliation of the granitic rock at the GTS [the mechanical properties of the granite at the GTS are taken from Nejati (2018)]. We argue that initiation of a tensile fracture is also possible at much lower tensile stresses if a pre-existing fracture or flaw is present.

Furthermore, accelerated deformation simultaneous to the $\mathrm{C} 4$ fracture formation observed between the shear zone S3.1 and S3.2 (Fig. 6, FBS1, sensor a, b) may additionally be indicative of substantial stress redistribution associated with differential slip along cluster $\mathrm{C} 1$ and the formation of cluster $\mathrm{C} 4$. The cumulative seismic moment of $\mathrm{C} 4$ is $2.3 \times 10^{4} \mathrm{Nm}$, neglecting the four large magnitude events associated with the near borehole-effect of the cemented strain monitoring borehole FBS2.

Cluster C2 (cumulative seismic moment: $4.6 \times 10^{5} \mathrm{Nm}$ ) forms an EW-striking steeply dipping structure south of cluster $\mathrm{C} 1$ and the S3.1 shear zone. The source mechanisms of cluster $\mathrm{C} 2$ reveal a downward movement of the rock volume in the southern block relative to the northern block, which is opposite to the mechanism of cluster $\mathrm{C} 1$. The difference-image of acoustic televiewer log images taken pre- and post-stimulation confirms the opposite slip directions of cluster C1 and C2 (Fig. 9). Similar to cluster C4, stress redistribution due to differential fracture slip along cluster $\mathrm{C} 1$ may explain the initiation and seismic mechanisms of cluster $\mathrm{C} 2$. However, source mechanisms of the $\mathrm{C} 2$ cluster remained consistent from the beginning and throughout the experiment, which implies that these source mechanisms were instead determined by the local stress conditions existing prior to the experiment, instead of stress redistribution during injection. Thus, we suggest that the opposite slip directions of clusters $\mathrm{C} 1$ and $\mathrm{C} 2$ are the consequence of substantial variations in the local stress field to the south and the north of the S3.1 shear zone.

Stress heterogeneity in our experimental volume is also evident from stress measurements (Krietsch et al. 2018a), which show that $\sigma_{2}$ and $\sigma_{3}$ are close in magnitude, and swap their orientation as they move from the unperturbed to the perturbed stress field estimates. Thus, variations at the metre scale in the local stress field 


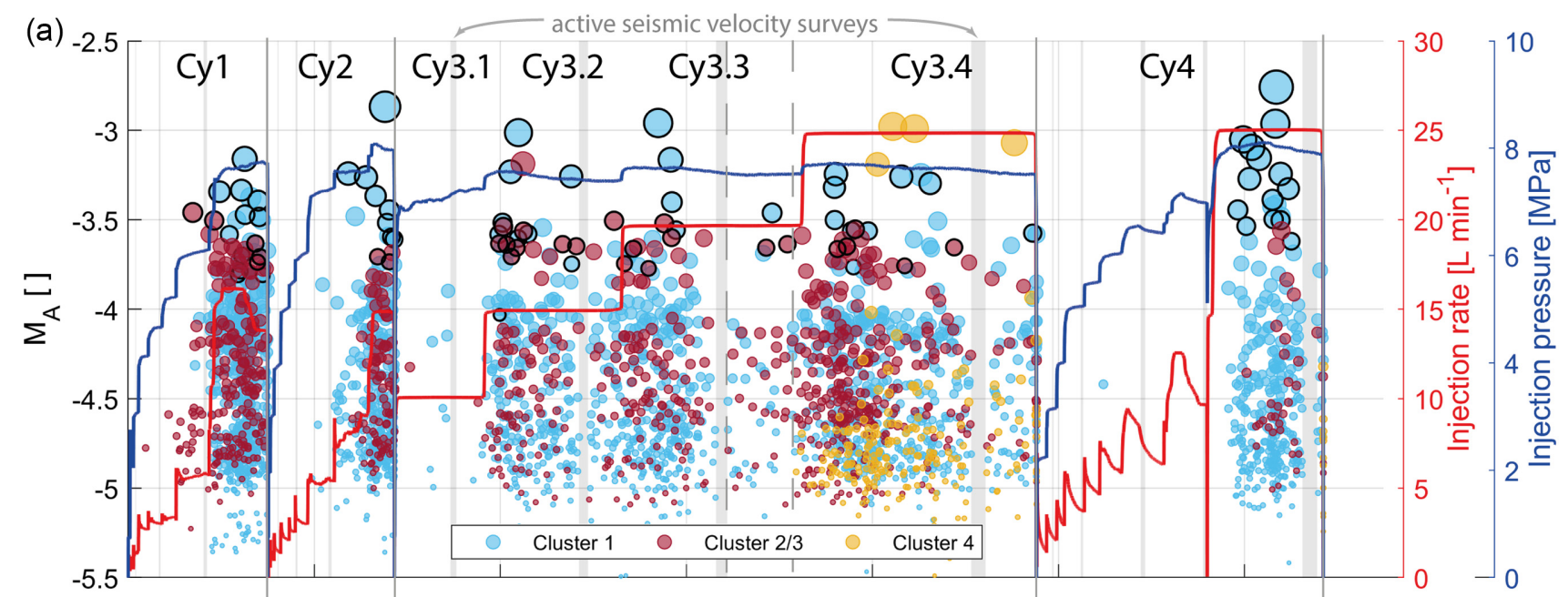

(b)

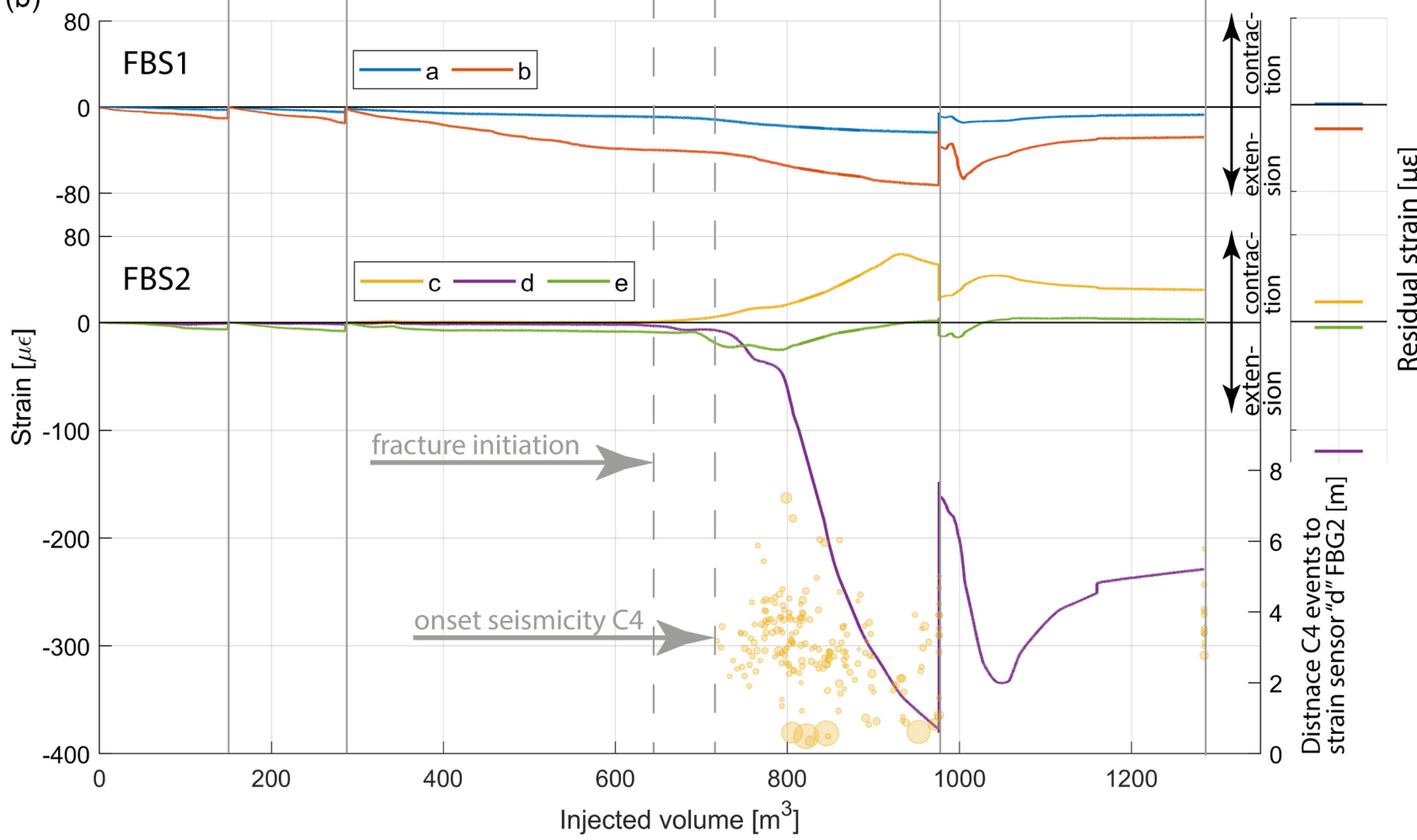

Figure 6. (a) Seismicity evolution and injection rate of the four injection cycles Cy1-Cy4 (the grey shaded areas show active seismic surveys in which seismic event detection was on hold). Seismic events for which MTs could be inferred are shown with black outlines, (b) strain measurements of the different strain monitoring intervals along with the occurrence of $\mathrm{C} 4$ seismicity with respect to the hit strain sensor 'd' in borehole FBS2. All observations are presented dependent on injected fluid volume (see supporting material S1 for a time resolved presentation of the same figure). The strain measurements are complimented by residual strain $16 \mathrm{hr}$ after the end of the stimulation experiment.

magnitudes and orientation, as well as in fracture orientation, may greatly influence the fault reactivation [i.e. permutations of principal stresses, (Hu \& Angelier 2004)]. To quantify this effect, we simulate the impact of stress field variations and fracture orientation on the source mechanisms of cluster $\mathrm{C} 2$. Results show that systematically increasing $\sigma_{3}$ and decreasing $\sigma_{2}$ on the mean MT plane of cluster $\mathrm{C} 2$ until permutation, leads to normal, strike-slip and finally to thrust faulting with the south block moving upwards with respect to the north block (see S12 for details). Thus, it is likely that the combination of stress heterogeneity and transient stress redistribution produced strongly variable source mechanisms during stimulation.

Stress field heterogeneity is also relevant for understanding natural seismicity. While the plate boundary forces control the dominant faulting styles especially of the largest events, substantial regional and local variations are possible at all scales (Zoback et al. 1989; Heidbach et al. 2007). Stress field heterogeneity was particularly observed after large events and close to the largest slip patches, for example after the Loma Prieta (Beroza \& Zoback 1993), the Landers and Hectors Mine (Wiemer et al. 2002) and the Tohoku 


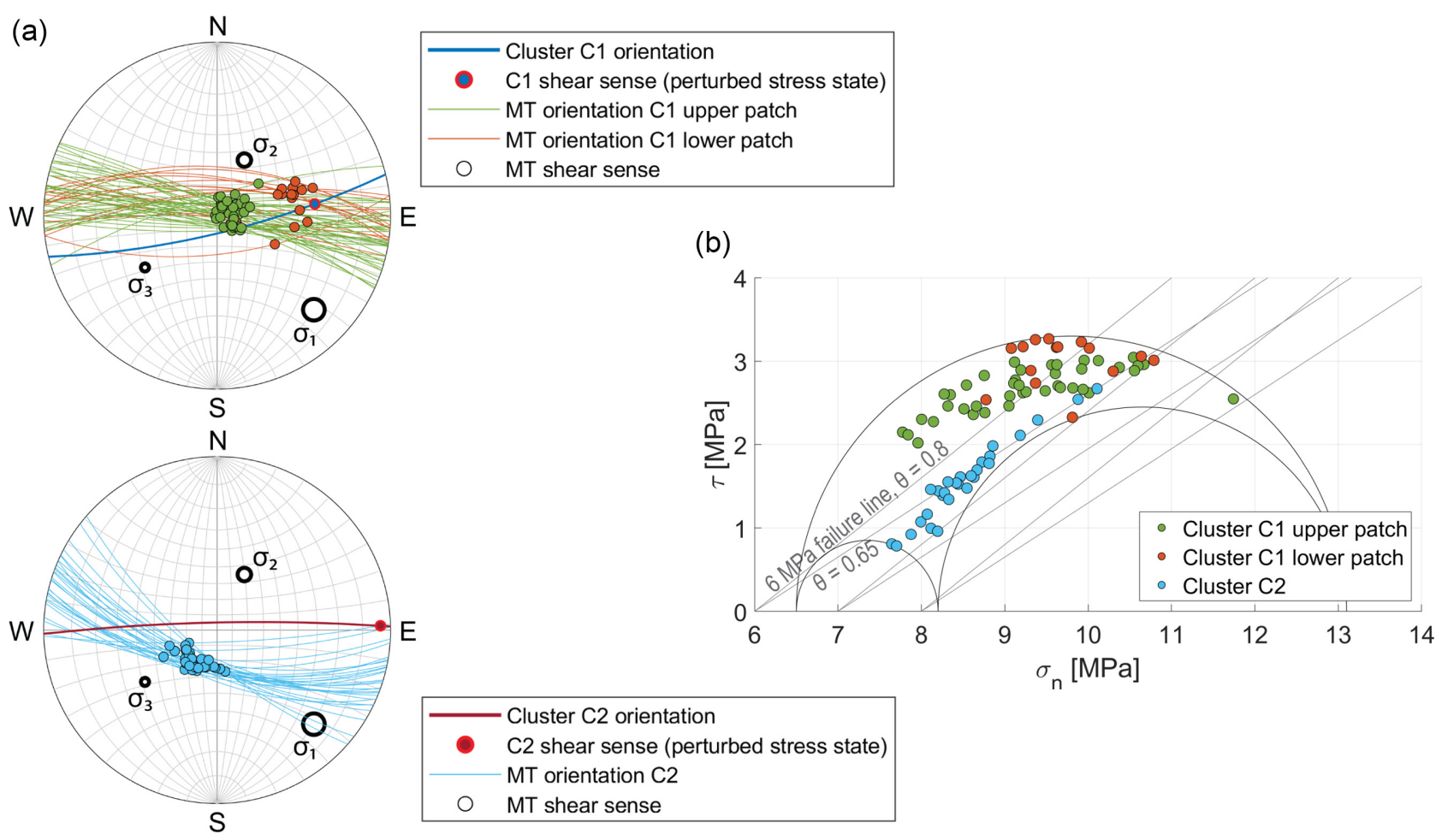

Figure 7. (a) Fault plane solutions of MTs of the different clusters and patches, the orientation of the best-fitting plane of the respective cluster and the shear sense one would expect assuming the perturbed stress state. All is presented in lower hemisphere stereographic projections. (b) Mohr Coulomb failure criterion assuming the perturbed stress state for the inferred MT fault planes along with failure pressure lines at 6,7 and $8 \mathrm{MPa}$ pore pressure, assuming an internal friction angle $\varphi$ of 0.65 and 0.8 , respectively (see S10 for the Mohr-Coulomb failure criterion assuming the unperturbed stress state).

earthquakes (Hardebeck 2012). It is assumed that earthquake slip can locally lead to a substantial, or even almost complete shear stress drop and to a highly heterogeneous stress field where aftershocks can occur at numerous fracture orientations implying stress field rotations (Beroza \& Zoback 1993; Wiemer et al. 2002; Hardebeck 2012; Yoshida et al. 2015). We argue that high pressure fluid injections can not only rupture faults unfavorably oriented in the stress field but also enable the sensing (through seismicity) of fracture networks, the prevailing stress field heterogeneity as well as stress redistribution by the high pressure fluid injection themselves.

\subsection{Interplay between seismicity and fluid flow}

Another important observation in our experiment are the streaky patterns of seismicity (i.e. subhorizontal alignments of hypocentres whose extent is larger along fracture planes in EW direction than in NS direction) within clusters and patches (Fig. 4). Most pronounced are the streaky patterns in the lower patch of cluster $\mathrm{C} 1$, where in addition an eastwards propagation can be observed (Fig. 4a). In natural fault systems, various authors report concentrated locations of earthquakes in streaks aligned in the direction of fault slip and seismically quiet zones. Streaks are seen as representing rheological transitions within fault zones or boundaries between creeping or locked sections of a fault (Rubin et al. 1999; Waldhauser et al. 2004; Rubinstein \& Beroza 2007). In our experiment, the directions of the streaks are almost perpendicular to the inferred slip directions from the moment tensors, unlike the cases in natural faults. However, apart from the scale our experiments differ from natural fault slip in that high pressure fluid injection induced fault slip.
Note also that the volume around the injection interval of about $0.5 \mathrm{~m}$ radius appears as seismically quiet zone for clusters $\mathrm{C} 1-\mathrm{C} 3$. Sparse seismicity around the injection interval may be explained by rate strengthening friction in the vicinity of the injection, where increased injection pressures promote aseismic creep as proposed by Cappa et al. (2019). However, another explanation may be that the injection interval intersects flow conduits represented by seismically quiet zones with seismicity in a streaky pattern on either side. Such conduits likely existed before the experiment, because the hydraulic conductivity of the interval was already high prior to the experiment and was not increased by stimulation (Krietsch et al. 2020b). Thus, seismicity was induced along the less conductive boundaries of the conduits that appear as highly seismogenic asperities. A similar model was proposed by Rutledge et al. (2004) and Evans et al. (2005) and is supported by observations from reservoir stimulations (Tezuka \& Niitsuma 2000). They proposed that slip along the shear zones is perpendicular to the flow direction that follows conduits that open in response to shear dilation along the rough surface (see Fig. 4b). The model agrees with the observed slip direction that is sub-perpendicular to the strike of the patterns within the clusters, and therefore provides a mechanism for the observed thrust/normal faulting.

\subsection{Submetre-scale complexity, forecastability and controllability}

A key implication of our work is related to forecasting and controlling induced seismicity during high-pressure injection for reservoir 

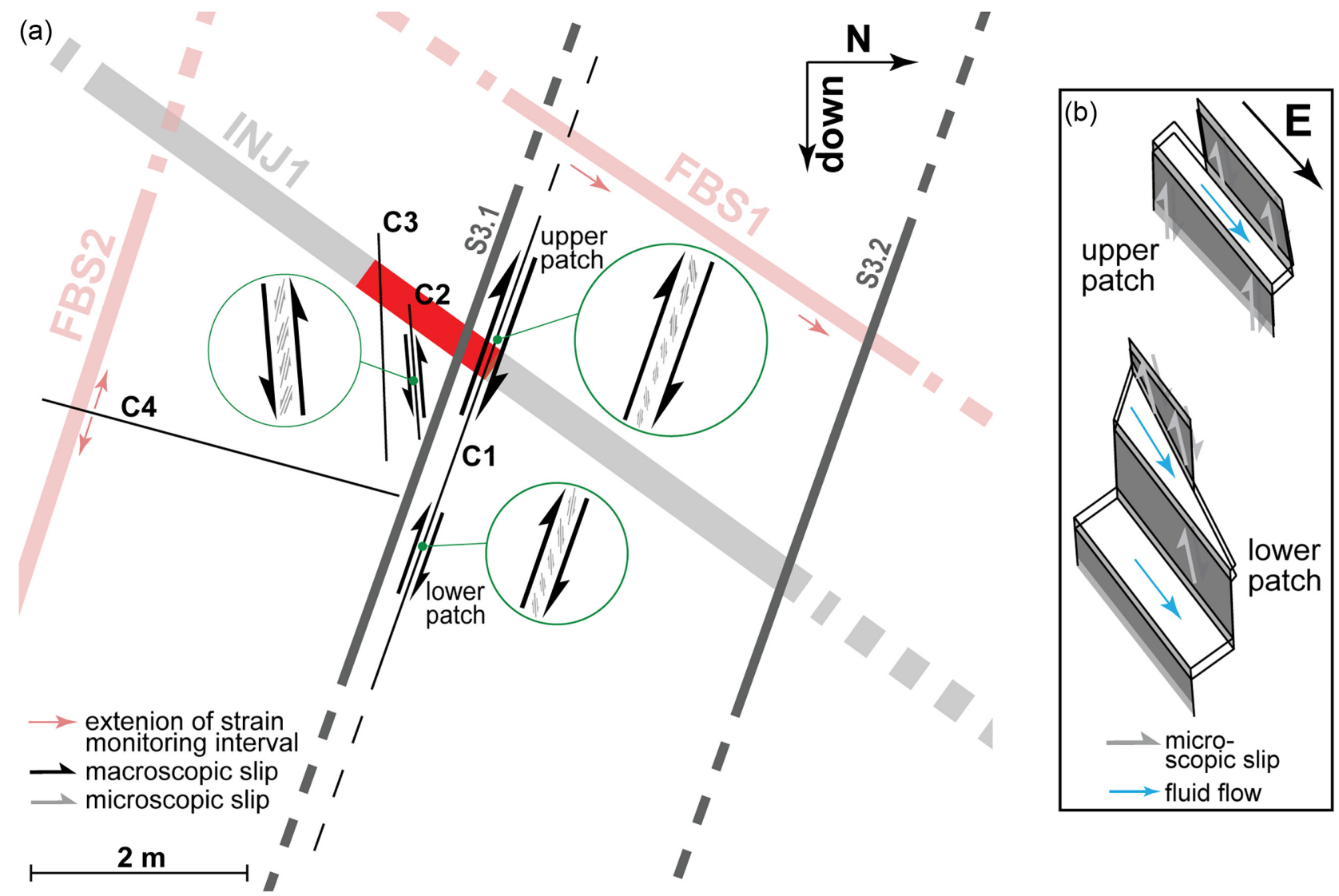

Figure 8. (a) Cross sectional schematic view towards west of the injection borehole (INJ1), the injection interval (red square), the clusterplains of the induced seismicity, with available microscopic and resulting macroscopic slip directions, along with the two shear zones S3.1 and S3.2. (b) conceptual flow field model in combination with the observed seismic slip plains at dip angles in normal, thrust faulting regimes of the upper and lower patch of cluster $\mathrm{C} 1$. At the lower patch a right lateral strike-slip component adds to the normal faulting component.

enhancement, which is relevant for risk assessment and risk mitigation. A number of EGS projects in the past, such as the ones in Basel (Haering et al. 2008) and Pohang (Lee et al. 2019b) have failed because operators were unable to foresee that larger earthquakes were imminent. Our results indicate that detailed forecasting of the seismicity evolution and fault reactivation pattern may be extremely challenging if not nearly impossible in a decametre volume despite extremely detailed prior geological and stress characterization. While we are able to retrospectively (and with considerable effort) build a conceptual model that explains the metre-scale observations, this is a long way from being able to reliably forecast the seismicity and fracture activation or even forecast their evolution while the seismic sequences are unfolding.

Extrapolating this submetre-scale complexity to the field scale would imply that the a priori risk assessment remains highly uncertain (e.g. Broccardo et al. 2020). Real-time risk assessment using data assimilation has been proposed to address the lack of a prior knowledge (e.g. Broccardo et al. 2017; Mignan et al. 2017). However, our results also highlight that the ability to learn from an evolving sequence is quite limited and somewhat unpredictable, because stress heterogeneity and unknown interactions may dominate the further development of injection related seismicity, limiting the forecasting horizon and increasing the uncertainty of Adaptive Traffic Light systems (Grigoli et al. 2017; Mignan et al. 2017).
The key question is how relevant the heterogeneity we observe here at the decametre scale is for the kilometre scale. Possibly, on the field scale encompassing a cubic kilometre the metre-scale stress heterogeneities average out, and the complex interaction within the fracture network associated with the stimulated fault system gives way to less complex and more predictable large scale processes that are determined by the bulk properties of the fault system. As for example in the seismicity associated to the Pohang EGS project, a more refined analysis of the seismic data collected during drilling and the different phases of stimulation could have allowed to identify the fault activated by the stimulation and recognize the high level of risk months before the $M_{\mathrm{W}} 5.5$ earthquake actually happened (Lee et al. 2019a).

Nonetheless, limited transferability between the metre and the kilometre-scale experiments would imply that stimulation processes become scale-variant. However, based on our results we cannot exclude that importance of heterogeneities are scale indeed invariant, greatly increasing the uncertainty in forecasting the future evolution of high pressure injections into basement rocks. Finally, more experiments on an increased scale (i.e. the hundred-metre-scale) are needed to answer this question. Apart from that, decametre scale heterogeneities certainly gain importance for the concept of selectively stimulate multiple short borehole intervals with comparatively small fluid volumes in an EGS reservoir [i.e. zonal insulation (Meier et al. 2015)]. 

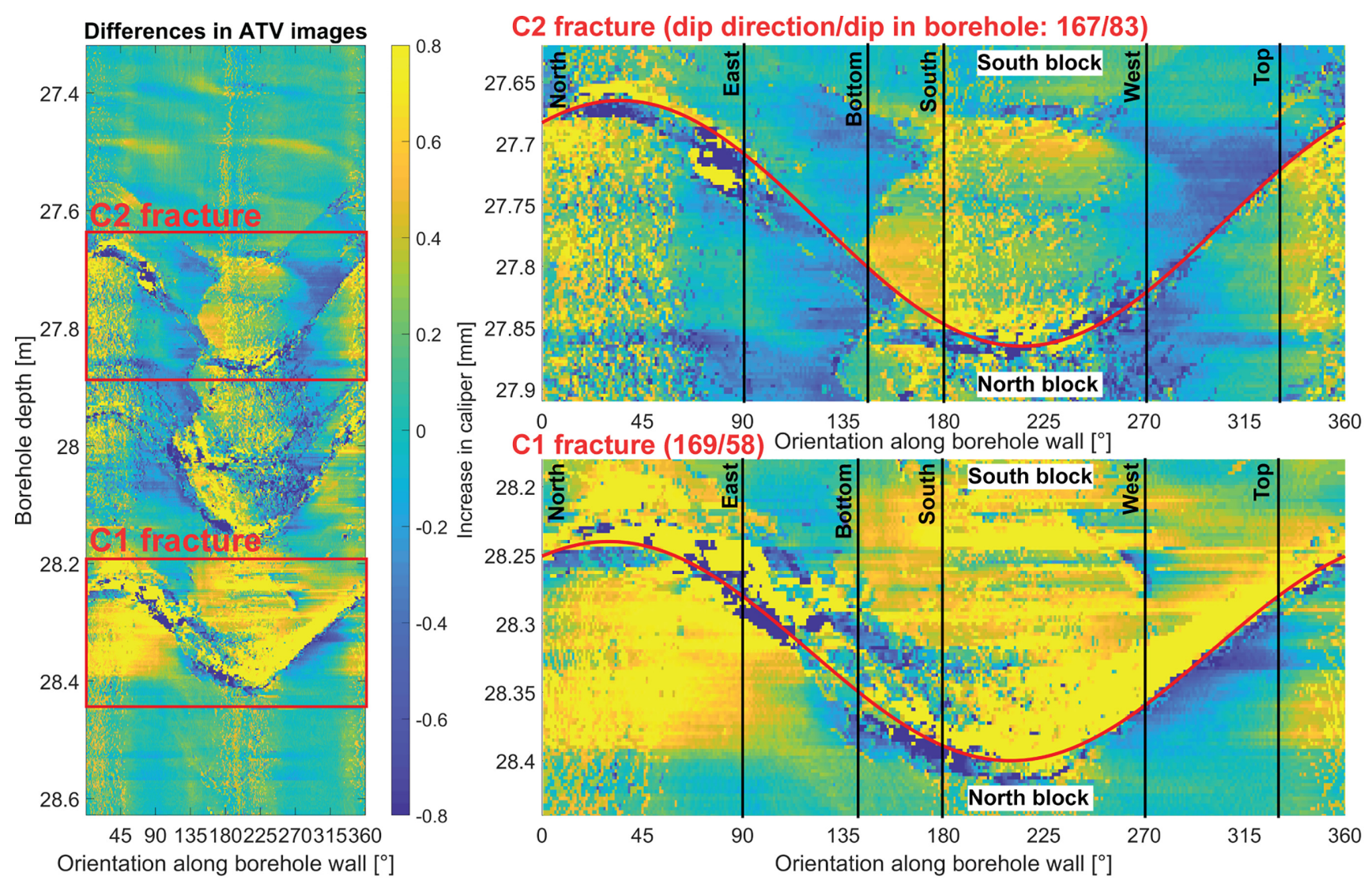

Figure 9. ATV difference image of the stimulated borehole interval, along with the cluster $\mathrm{C} 1$ and $\mathrm{C} 2$ associated fractures in a detailed view. The most pronounced contrast in caliper can be observed at the top of the $\mathrm{C} 1$ and $\mathrm{C} 2$ fractures, north and south of the target shear zone S3.1. The top part of the $\mathrm{C} 1$ fracture suggests an upward movement of the borehole volume in the south of the fracture (i.e. an increase in caliper), whereas the top part of the $\mathrm{C} 2$ fracture suggests a downward movement of the borehole volume in the south (i.e. a decrease in caliper). The remaining parts of the image of rather diffuse quality show potential borehole wall damage in the area of the fractures and the metabasic dyke (target shear zone S3.1).

\section{CONCLUSION}

Hydraulic stimulation of $1 \mathrm{~m}$ interval intersecting a brittle-ductile shear zone led to the deformation of three preexisting fractures in the damage zone surrounding a low-permeability fault core. Most slip occurred on one of these fractures in reverse to normal faulting mechanisms partially with strike slip influence. Thus, slip directions and faulting styles only partially agree with the predicted right-lateral to oblique reverse faulting predicated from the a priori measured stress state. Furthermore, opposite slip directions and mostly normal faulting were observed along a fracture only $0.5 \mathrm{~m}$ away from the predominantly stimulated fracture. We argue that a heterogeneous static stress field prevails on the submetre-scale and is further modified through transient slip- and pressure-induced stress redistribution during injection. Initiation of a tensile dominated fracture, possibly induced by a change in slip magnitude within a short distance of a metre along the predominantly stimulated fracture, supports the substantial role of stress redistribution over the course of injection. Clustered and characteristically aligned seismicity possibly suggests fluid flow in permeable conduits. The observed complex interplay between the pre-existing fracture network of the fault damage zone with a stress field that varies within metres and is further modified by transient stress redistribution implies that forecasting and anticipating permeability creation and the associated induced hazard is highly challenging on the decametre scale. Upscaling such complexity towards the field scale EGS projects remains unresolved and requires further experiments at intermediate scales.

\section{ACKNOWLEDGEMENTS}

This study is part of the In situ Stimulation and Circulation (ISC) project established by the Swiss Competence Center for Energy Research - Supply of Electricity (SCCER-SoE) with the support of Innosuisse. Funding for the ISC project was provided by the ETH Zurich Foundation with grants from Shell and EWZ and by the Swiss Federal Office of Energy through a P\&D grant. Linus Villiger is supported by ETH Zurich Research Grant ETH-35 16-1; Hannes Krietsch is supported by SNF grant 200021_169178. GK acknowledges support from the Deutsche Forschungsgemeinschaft (DFG), grant KW 84/4-1. The Grimsel Test Site is operated by Nagra, the National Cooperative for the Disposal of Radioactive Waste. We are indebted to Nagra for hosting the ISC project in their facility and to the Nagra technical staff for onsite support. All data used for the analysis in this articel are available on the ETH Zurich Research Collection at https://doi.org/10.3929/ethz-b-000280357. 


\section{REFEREN CES}

Amann, F. et al., 2018. The seismo-hydromechanical behavior during deep geothermal reservoir stimulations: open questions tackled in a decameterscale in situ stimulation experiment, Solid Earth, 9(1), 115-137.

Andersen, L., 2001. A Relative Moment Tensor Inversion Technique Applied to Seismicity Induced by Mining, University of the Witwatersrand.

Baujard, C., Genter, A., Dalmais, E., Maurer, V., Hehn, R., Rosillette, R., Vidal, J. \& Schmittbuhl, J., 2017. Hydrothermal characterization of wells GRT-1 and GRT-2 in Rittershoffen, France: implications on the understanding of natural flow systems in the Rhine Graben, Geothermics, $\mathbf{6 5}$, 255-268.

Baumgaertner, J., Hettkamp, T., Teza, D., Kölbel, T., Mergner, H., Schlagermann, P. \& Lerch, C., 2013. Betriebserfahrungen mit den Geothermiekraftwerken Landau, Insheim und Bruchsal. bbr Leitungsbau, Brunnenbau, Geothermie, 64, 48-57.

Bell, J., Caillet, G. \& Adams, J., 1992. Attempts to detect open fractures and non-sealing faults with dipmeter logs, Geol. Soc., Lond., Spec. Publ., 65(1), 211-220.

Beroza, G.C. \& Zoback, M.D., 1993. Mechanism diversity of the Loma Prieta aftershocks and the mechanics of mainshock-aftershock interaction, Science, 259(5092), 210-213.

Bhattacharya, P. \& Viesca, R.C., 2019. Fluid-induced aseismic fault slip outpaces pore-fluid migration, Science, 364(6439), 464-468.

Blake, K., 2013, Stress analysis for boreholes on Department of Defense Lands in the Western United States: a study in stress heterogeneity, in Proceedings of the Thirty-Eighth Workshop on Geothermal Reservoir Engineering, Stanford Univ., Stanford, CA.

Brixel, B., Klepikova, M., Jalali, M., Lei, Q., Roques, C., Krietsch, H. \& Loew, S., 2020. Tracking fluid flow in shallow crustal fault zones: 1. Insights from single-hole permeability estimates, J. geophys. Res., 125, 4, doi:10.1029/2019JB018200.

Broccardo, M., Mignan, A., Wiemer, S., Stojadinovic, B. \& Giardini, D., 2017. Hierarchical Bayesian modeling of fluid-induced seismicity, Geophys. Res. Lett., 44(22), 11357-11367.

Broccardo, M. et al., 2020. Induced seismicity risk analysis of the hydraulic stimulation of a geothermal well on Geldinganes, Iceland, Nat. Hazards Earth Syst. Sci. (NHESS), 20, 1573-1593.

Bruno, M.S. \& Winterstein, D.F., 1994. Some influences of stratigraphy and structure on reservoir stress orientation, Geophysics, 59(6), 954-962.

Cappa, F., Scuderi, M.M., Collettini, C., Guglielmi, Y. \& Avouac, J.-P., 2019. Stabilization of fault slip by fluid injection in the laboratory and in situ, Sci. Adv., 5(3), doi:10.1126/sciadv.aau4065.

Catalli, F., Meier, M.A. \& Wiemer, S., 2013. The role of Coulomb stress changes for injection-induced seismicity: the Basel enhanced geothermal system, Geophys. Res. Lett., 40(1), 72-77.

Cesca, S., Rohr, A. \& Dahm, T., 2013. Discrimination of induced seismicity by full moment tensor inversion and decomposition, J. Seismol., 17(1), $147-163$.

Cornet, F., Helm, J., Poitrenaud, H. \& Etchecopar, A., 1997. Seismic and aseismic slips induced by large-scale fluid injections, in Seismicity Associated with Mines, Reservoirs and Fluid Injections, pp. 563-583, Springer.

Doetsch, J., Krietsch, H., Schmelzbach, C., Jalali, M.R., Gischig, V., Villiger, L., Amann, F. \& Maurer, H., 2020. Characterizing a decametre-scale granitic reservoir using GPR and seismic methods - a case study for preparing hydraulic stimulations, Solid Earth, 11, 1441-1455.

Dutler, N., Valley, B., Gischig, V., Villiger, L., Krietsch, H., Doetsch, J., Brixel, B. \& Amann, F., 2019. Hydraulic fracture propagation in a heterogeneous stress field in a crystalline rock mass, Solid Earth, 10(6), 1877-1904, doi:10.5194/se-10-1877-2019.

Eshelby, J.D., 1957. The determination of the elastic field of an ellipsoidal inclusion, and related problems, Proc. R. Soc. Lond., A, 241(1226), 376396.

Evans, K. et al., 2005. Microseismicity and permeability enhancement of hydrogeologic structures during massive fluid injections into granite at $3 \mathrm{~km}$ depth at the Soultz HDR site, Geophys. J. Int., 160(1), 388-412.

Frohlich, C., 1992. Triangle diagrams: ternary graphs to display similarity and diversity of earthquake focal mechanisms, Physics of the Earth and Planetary interiors, 75(1-3), 193-198.
Genter, A., Evans, K., Cuenot, N., Fritsch, D. \& Sanjuan, B., 2010. Contribution of the exploration of deep crystalline fractured reservoir of Soultz to the knowledge of enhanced geothermal systems (EGS), C.R. Geosci., 342(7-8), 502-516.

Gischig, V.S. et al., 2019. Hydraulic stimulation and fluid circulation experiments in underground laboratories: stepping up the scale towards engineered geothermal systems, Geomech. Ener. Environ., 24,

Goebel, T., Weingarten, M., Chen, X., Haffener, J. \& Brodsky, E.(2017). The 2016 Mw5. 1 Fairview, Oklahoma earthquakes: evidence for long-range poroelastic triggering at $>40 \mathrm{~km}$ from fluid disposal wells, Earth planet. Sci. Lett., 472, 50-61.

Goodfellow, S., Nasseri, M., Maxwell, S. \& Young, R., 2015. Hydraulic fracture energy budget: insights from the laboratory, Geophys. Res. Lett., 42(9), 3179-3187.

Grigoli, F. et al., 2017. Current challenges in monitoring, discrimination, and management of induced seismicity related to underground industrial activities: a European perspective, Rev. Geophys., 55(2), 310-340.

Guglielmi, Y., Cappa, F., Avouac, J.-P., Henry, P. \& Elsworth, D., 2015. Seismicity triggered by fluid injection-induced aseismic slip, Science, 348(6240), 1224-1226

Haering, M.O., Schanz, U., Ladner, F. \& Dyer, B.C., 2008. Characterisation of the Basel 1 enhanced geothermal system, Geothermics, 37(5), 469495.

Hardebeck, J.L., 2012. Coseismic and postseismic stress rotations due to great subduction zone earthquakes, Geophys. Res. Lett., 39(21), doi:10.1029/2012GL053438.

Heidbach, O., Reinecker, J., Tingay, M., Müller, B., Sperner, B., Fuchs, K. \& Wenzel, F., 2007. Plate boundary forces are not enough: second-and third-order stress patterns highlighted in the World Stress Map database, Tectonics, 26(6), doi:10.1029/2007TC002133.

Hirschberg, S., Wiemer, S. \& Burgherr, P., 2014. Energy from the Earth: Deep Geothermal as a Resource for the Future?, Vol. 62, vdf Hochschulverlag AG.

Hudson, J., Pearce, R. \& Rogers, R., 1989. Source type plot for inversion of the moment tensor, J. of Geophysical Res.: Solid Earth, 94(B1), 765-774.

Hu, J.C. \& Angelier, J., 2004. Stress permutations: three-dimensional distinct element analysis accounts for a common phenomenon in brittle tectonics, J. geophys. Res., 109(B9), doi:10.1029/2003JB002616.

Jalali, M., Gischig, V., Doetsch, J., Näf, R., Krietsch, H., Klepikova, M., Amann, F. \& Giardini, D., 2018. Transmissivity changes and microseismicity induced by small scale hydraulic fracturing tests in crystalline rock, Geophys. Res. Lett., 45(5), 2265-2273.

Keusen, H., Ganguin, J., Schuler, P. \& Buletti, M., 1989. Grimsel Test Site: Geology, Retrieved from: https://inis.iaea.org/search/search.aspx?orig_q=RN:21046305.

King, G.C., Stein, R.S. \& Lin, J., 1994. Static stress changes and the triggering of earthquakes, Bull. seism. Soc. Am., 84(3), 935-953.

Kirsch, C., 1898. Die theorie der elastizitat und die bedurfnisse der festigkeitslehre, Zeitschrift des Vereines Deutscher Ingenieure, 42, 797-807.

Krietsch, H., Doetsch, J., Dutler, N., Jalali, M., Gischig, V., Loew, S. \& Amann, F., 2018a. Comprehensive geological dataset describing a crystalline rock mass for hydraulic stimulation experiments, Scient. Data, $\mathbf{5}$, 180269.

Krietsch, H., Gischig, V., Evans, K., Doetsch, J., Dutler, N.O., Valley, B. \& Amann, F., 2018b. Stress measurements for an in situ stimulation experiment in crystalline rock: integration of induced seismicity, stress relief and hydraulic methods, Rock Mech. Rock Eng., 52, 517-542.

Krietsch, H. et al., 2020a. Hydromechanical processes and their influence on the stimulation effected volume: observations from a decameter-scale hydraulic stimulation project, Solid Earth, 11(5), 1699-1729.

Krietsch, H. et al., 2020b. Hydro-mechanical processes and their influence on the stimulated volume: observations from a decameter-scale hydraulic stimulation experiment, Solid Earth, 11, 1699-1729.

Kwiatek, G., Martínez-Garzón, P. \& Bohnhoff, M., 2016. HybridMT: a MATLAB/shell environment package for seismic moment tensor inversion and refinement, Seismol. Res. Lett., 87(4), 964-976.

Kwiatek, G., Plenkers, K., Dresen, G. \& Group, J.R., 2011. Source parameters of picoseismicity recorded at Mponeng deep gold mine, South 
Africa: implications for scaling relations, Bull. seism. Soc. Am., 101(6), 2592-2608.

Lee, K., Yeo, I., Lee, J., Kang, T., Rhie, J., Sheen, D. \& Oh, S., . ., 2019 b. Summary report of the Korean Government Commission on relations between the 2017 Pohang earthquake and the EGS project, Geological Society of Korea and Korean Government Commission on the Cause of the Pohang Earthquake 205.

Lee, K.-K. et al., 2019a. Managing injection-induced seismic risks, Science, 364(6442), 730-732.

Lin, W., Yeh, E.-C., Hung, J.-H., Haimson, B. \& Hirono, T., 2010. Localized rotation of principal stress around faults and fractures determined from borehole breakouts in hole B of the Taiwan Chelungpu-fault Drilling Project (TCDP), Tectonophysics, 482(1-4), 82-91.

Manthei, G., Eisenblätter, J., Spies, T. \& Eilers, G., 2001. Source parameters of acoustic emission events in salt rock, J. Acoust. Emission, 19, 100-108.

Martinez Garzon, P., Bohnhoff, M., Kwiatek, G. \& Dresen, G., 2013. Stress tensor changes related to fluid injection at The Geysers geothermal field, California, Geophys. Res. Lett., 40(11), 2596-2601.

Martinez Garzon, P., Kwiatek, G., Bohnhoff, M. \& Dresen, G., 2016. Impact of fluid injection on fracture reactivation at the Geysers geothermal field, J. geophys. Res., 121(10), 7432-7449.

Martinez Garzon, P., Kwiatek, G., Bohnhoff, M. \& Dresen, G., 2017. Volumetric components in the earthquake source related to fluid injection and stress state, Geophys. Res. Lett., 44(2), 800-809.

Martinez Garzon, P., Kwiatek, G., Sone, H., Bohnhoff, M., Dresen, G. \& Hartline, C., 2014. Spatiotemporal changes, faulting regimes, and source parameters of induced seismicity: a case study from the Geysers geothermal field, J. geophys. Res., 119(11), 8378-8396.

McNamara, D.D., Massiot, C., Lewis, B. \& Wallis, I.C., 2015. Heterogeneity of structure and stress in the Rotokawa Geothermal Field, New Zealand, J. geophys. Res., 120(2), 1243-1262.

Meier, P.M., Rodríguez, A.A. \& Bethmann, F., 2015. Lessons learned from Basel: new EGS projects in Switzerland using multistage stimulation and a probabilistic traffic light system for the reduction of seismic risk, in Proceedings of World Geothermal Congress 2015, Melbourne, 19-25 April 2015.

Mignan, A., Broccardo, M., Wiemer, S. \& Giardini, D., 2017. Induced seismicity closed-form traffic light system for actuarial decision-making during deep fluid injections, Sci. Rep., 7(1), 13607.

Nandan, S., Ouillon, G., Sornette, D. \& Wiemer, S., 2019. Forecasting the rates of future aftershocks of all generations is essential to develop better earthquake forecast models, J. geophys. Res., 124(8), 8404-8425.

Nejati, M., 2018, On the anisotropy of mechanical properties in Grimsel Granodiorite, ETH Zurich, Swiss Competence Center for Energy Research - Supply of Electricity, Retrieved from https://doi.org/10.3929/ethz-b000289969

Nie, X., Zou, C., Pan, L., Huang, Z. \& Liu, D., 2013. Fracture analysis and determination of in-situ stress direction from resistivity and acoustic image $\operatorname{logs}$ and core data in the Wenchuan Earthquake Fault Scientific Drilling Borehole-2 (50-1370 m), Tectonophysics, 593, 161-171.

Pahl, A., Heusermann, S., Bräuer, V. \& Glöggler, W., 1989. Grimsel Test Site. Rock Stress Investigations, BGR-NAGRA Rep. NTB,Hannover, Germany, 945.

Rubin, A.M., Gillard, D. \& Got, J.-L., 1999. Streaks of microearthquakes along creeping faults, Nature, 400(6745), 635-641.

Rubinstein, J.L. \& Beroza, G.C., 2007. Full waveform earthquake location: application to seismic streaks on the Calaveras fault, California, $J$. geophys. Res., 112(B5), doi:10.1029/2006JB004463.

Rutledge, J.T., Phillips, W.S. \& Mayerhofer, M., 2004. Faulting induced by forced fluid injection and fluid flow forced by faulting: an interpretation of hydraulic-fracture microseismicity, Carthage Cotton Valley gas field, Texas, Bull. seism. Soc. Am., 94(5), 1817-1830.

Schoenball, M., Baujard, C., Kohl, T. \& Dorbath, L., 2012. The role of triggering by static stress transfer during geothermal reservoir stimulation, J. geophys. Res., 117(B9), doi:10.1029/2012JB009304.

Schoenball, M., Dorbath, L., Gaucher, E., Wellmann, J.F. \& Kohl, T., 2014. Change of stress regime during geothermal reservoir stimulation, Geophys. Res. Lett., 41(4), 1163-1170.
Schorlemmer, D., Wiemer, S. \& Wyss, M., 2005. Variations in earthquakesize distribution across different stress regimes, Nature, 437(7058), 539542.

Segall, P. \& Lu, S., 2015. Injection-induced seismicity: poroelastic and earthquake nucleation effects, J. geophys. Res., 120(7), 5082-5103.

Stierle, E., Vavryčuk, V., Kwiatek, G., Charalampidou, E.-M. \& Bohnhoff, M., 2016. Seismic moment tensors of acoustic emissions recorded during laboratory rock deformation experiments: sensitivity to attenuation and anisotropy, Geophys. Suppl. Mon. Not. R. Astron. Soc., 205(1), 38-50.

Tezuka, K. \& Niitsuma, H., 2000. Stress estimated using microseismic clusters and its relationship to the fracture system of the Hijiori hot dry rock reservoir, Developments in Geotechnical Engineering, Vol., 84, pp. 55-70, Elsevier.

Valley, B. \& Evans, K.F., 2009. Stress orientation to $5 \mathrm{~km}$ depth in the basement below Basel (Switzerland) from borehole failure analysis, Swiss J. Geosci., 102(3), 467.

Valley, B. \& Evans, K.F., 2010. Stress heterogeneity in the granite of the Soultz EGS reservoir inferred from analysis of wellbore failure, in Paper presented at the Proceedings World Geothermal Congress 2010.

Valley, B. \& Evans, K.F., 2019. Stress magnitudes in the Basel enhanced geothermal system, Int. J. Rock Mech. Min. Sci., 118, 1-20.

Villiger, L. et al., 2020. Influence of reservoir geology on seismic response during decameter scale hydraulic stimulations in crystalline rock, Solid Earth, 11(2), 627-655.

Waldhauser, F., Ellsworth, W.L., Schaff, D.P. \& Cole, A., 2004. Streaks, multiplets, and holes: high-resolution spatio-temporal behavior of Parkfield seismicity, Geophys. Res. Lett., 31(18), doi:10.1029/2004g1020649.

Wenning, Q.C., Madonna, C., de Haller, A. \& Burg, J.-P., 2018. Permeability and seismic velocity anisotropy across a ductile-brittle fault zone in crystalline rock, Solid Earth, 9(3), 683-698.

Wiemer, S., Gerstenberger, M. \& Hauksson, E., 2002. Properties of the aftershock sequence of the $1999 \mathrm{M} \mathrm{w} 7.1$ Hector Mine earthquake: implications for aftershock hazard, Bull. seism. Soc. Am., 92(4), 1227-1240.

Wileveau, Y., Cornet, F., Desroches, J. \& Blumling, P., 2007. Complete in situ stress determination in an Argillite sedimentary formation, Phys. Chem. Earth, Parts A/B/C, 32(8-14), 866-878.

Yoshida, K., Hasegawa, A. \& Okada, T., 2015. Spatially heterogeneous stress field in the source area of the $2011 \mathrm{M} \mathrm{w}$ 6.6 Fukushima-Hamadori earthquake, NE Japan, probably caused by static stress change, Geophys. J. Int., 201(2), 1062-1071.

Zoback, M.L. et al., 1989. Global patterns of tectonic stress, Nature, 341(6240), 291-298.

\section{SUPPORTING INFORMATION}

Supplementary data are available at $G J I$ online.

Figure S1: (a) Seismicity evolution and injection rate of the four injection cycles Cy1-Cy4 (the grey shaded areas show periods in which passive seismic event detection was on hold and active seismic surveys were performed), seismic events for which an MT could be inferred are outlined in black, (b) displays strain measurements of the different strain monitoring intervals. All observations are presented dependent on elapsed time since the beginning of the experiment. The strain measurements are complimented by residual strain measured in the same monitoring intervals 16 hours after the end of the stimulation experiment.

Figure S2: General angle convention of (a) sparker source, tunnel AE sensor (R2-R15) configuration and (b) piezoelectric source in borehole, borehole AE sensor (R16-R27) configuration.

Figure S3: (a) $Q_{p}$ estimates versus root mean square (RMS) error of linear fit between pick and rise time of the first motion $P$-wave amplitude. (b) Top view and (c) side view of spatial distribution of $Q_{p}$ estimates along location of ignited sparker shots.

Figure S4: (a) An example of corrected first motion $P$-wave amplitudes recorded within a sparker angle range from $80^{\circ}$ to $90^{\circ}$. A 
correction of the amplitudes using a $Q$ of 62 best minimizes the scatter in $10^{\circ}$ incidence angle bins. (b) $Q$ estimates of different sparker angle bins.

Figure S5: (a) Calibration of sparker source radiation pattern at a $Q$ of 30 and (b) a $Q$ of 60 .

Figure S6: (a)-(c) Corrected amplitudes of first motion $P$-wave pulses of sparker shots versus incidence angle on tunnel sensors (R2-R15) assuming $Q$ values of 20, 60 and 120. The red dots represent the 95 per cent confidence interval of measurements in $10^{\circ}$ incidence angle bins. Panel (d) shows the incidence angle and $Q$ dependent amplitude variations of tunnel AE sensors.

Figure S7: (a)-(c) Corrected amplitudes of first motion $P$-wave pulses of the piezoelectric source versus incidence angle on borehole sensors (R16-R27) assuming $Q$ values of 20, 60 and 120 (references to the observed maximum amplitude). The colour code represents the distance between piezoelectric source and sensor. The red dots are the 95 per cent confidence interval of measurements in $10^{\circ}$ incidence angle bins. Panel (d) shows the incidence angle and $Q$ dependent amplitude variations of borehole AE sensors.

Figure S8: (a) BIC criterion of the 84 MTs colour-coded according to RMSE. In (b) the unique event ID was added to the subfigure.

Figure S9: (a) Moment correction factors for 1st round of iterations along with (b) polarity matches. (c) 2nd round of iterations along with (d) polarity matches.

Figure S10: Kagan angles, RMS and $E_{\text {MAX }}$ for (a) DCMTs and (b) FMTs.

Figure S11: Chosen DCMTs randomly perturbed with 10 per cent input amplitude variation, and $\pm 5^{\circ}$ random variation of the take-off angle (blue, green and red nodal lines correspond to the normal, strike-slip and thrust faulting, respectively.

Figure S12: Chosen FMTs randomly perturbed with 10 per cent input amplitude variation, and $\pm 5^{\circ}$ random variation of the take-off angle (blue, green and red nodal lines correspond to the normal, strike-slip and thrust faulting, respectively).

Figure S13: Identification of fault planes (FP) and auxiliary planes (AP) of MTs for (a) cluster $\mathrm{C} 1$ and (b) cluster $\mathrm{C} 2 \mathrm{a}$, presented in lower hemisphere stereographic projections.

Figure S14: Properties of all fault planes, along with the corresponding faulting styles following the convention introduced by Frohlich (1992).

Figure S15: (a) Fault planes of MTs and shear sense according to the near field stress state and (b) the far field stress state in lower hemisphere stereographic projections.

Figure S16: Mohr Coulomb failure pressures for inferred fault planes in (a) NF and (b) FF stress state. The diagonal lines represent the failure pressure at an internal friction angle of 0.65 and 0.8 , respectively.

Figure S17: (a) Non-double-couple characteristics of inferred FMTs (Hudson et al. 1989). Panel (b) distance from injection interval versus the ISO component.

Figure S18: ISO component of FMTs using a $Q$ of 60 along with injection rate and injection pressure dependent on cumulative injected fluid volume.

Figure S19: Variation of $\sigma_{2}$ and $\sigma_{3}$ magnitudes and permutation of $\sigma_{2}$ and $\sigma_{3}$ directions in (a) the perturbed stress field and (b) the unperturbed stress field at the $\mathrm{C} 2$ and the mean C2 MT plane presented in lower hemisphere stereographic projections.

\section{GJI_animated_figure_v01.zip}

Please note: Oxford University Press is not responsible for the content or functionality of any supporting materials supplied by the authors. Any queries (other than missing material) should be directed to the corresponding author for the paper. 